OPEN ACCESS

Edited by:

James Korkola,

Oregon Health and Science

University, United States

Reviewed by:

Yang Shen,

Southeast University, China

Li Wu,

University of Chinese Academy of Sciences, China

*Correspondence:

Ge Zhang

zhangge@hkbu.edu.hk

${ }^{t}$ These authors share first authorship

Specialty section:

This article was submitted to

Molecular Medicine,

a section of the journal

Frontiers in Cell and Developmental

Biology

Received: 07 November 2020

Accepted: 25 February 2021

Published: 29 March 2021

Citation:

Ma Y, Yu S, Ni S, Zhang B, Kung ACF, Gao J, Lu A and Zhang G (2021) Targeting Strategies for Enhancing Paclitaxel Specificity

in Chemotherapy.

Front. Cell Dev. Biol. 9:626910.

doi: 10.3389/fcell.2021.626910

\section{Targeting Strategies for Enhancing Paclitaxel Specificity in Chemotherapy}

\author{
Yuan Ma $\mathrm{a}^{1,2,3,44}$, Sifan $\mathrm{Yu}^{1,2,44}$, Shuaijian $\mathrm{Ni}^{1,2,3,4}$, Baoxian Zhang ${ }^{4,5}$, Angela Chun Fai Kung ${ }^{4,5}$, \\ Jin Gao ${ }^{4,6}$, Aiping Lu ${ }^{1,2,3,4}$ and Ge Zhang ${ }^{1,2,3,4 *}$ \\ ${ }^{1}$ Law Sau Fai Institute for Advancing Translational Medicine in Bone and Joint Diseases, School of Chinese Medicine, Hong \\ Kong Baptist University, Kowloon, Hong Kong, ${ }^{2}$ Institute of Integrated Bioinfomedicine and Translational Science, School of \\ Chinese Medicine, Hong Kong Baptist University, Kowloon, Hong Kong, ${ }^{3}$ Institute of Precision Medicine and Innovative Drug \\ Discovery, HKBU Institute for Research and Continuing Education, Shenzhen, China, ${ }^{4}$ Increasepharm and Hong Kong \\ Baptist University Joint Centre for Nucleic Acid Drug Discovery, Hong Kong Science Park, New Territories, Hong Kong, \\ ${ }^{5}$ Increasepharm (Hong Kong) Limited, Hong Kong Science Park, Shatin, Hong Kong, ${ }^{6}$ Increasepharm (Hengqin) Institute \\ Co. Limited, Zhuhai, China
}

Paclitaxel (PTX) has been used for cancer treatment for decades and has become one of the most successful chemotherapeutics in the clinic and financially. However, serious problems with its use still exist, owing to its poor solubility and non-selective toxicity. With respect to these issues, recent advances have addressed the water solubility and tumor specificity related to PTX application. Many measures have been proposed to remedy these limitations by enhancing tumor recognition via ligandreceptor-mediated targeting as well as other associated strategies. In this review, we investigated various kinds of ligands that have emerged as PTX tumor-targeting tools. In particular, this article highlights small molecule-, protein-, and aptamer-functionalized conjugates and nanoparticles (NPS), providing a promising approach for PTX-based individualized treatment prospects.

Keywords: paclitaxel, ligand, small molecule, antibody, aptamer

\section{INTRODUCTION}

Paclitaxel (PTX) is a natural terpenoid bearing a tricyclic skeleton. It is an alkaline power taxine after isolation from the leaves of the European yew, formerly performed by German scientist Lucas in 1865. PTX was registered as the trademark Taxol ${ }^{\mathrm{TM}}$ in 1992 by Bristol-Myers Squibb Company (Weaver, 2014) and approved by the US Food and Drug Administration (FDA) for the treatment of gastric cancer. Due to the increasing demands of the market, breakthroughs in synthetic methodologies have significantly accelerated PTX development. To date, several PTX agents have entered into different stages of clinical trials (shown in Table 1) and have been widely used for the treatment of gastric cancer, breast cancer, ovarian cancer, melanoma, lung cancer, head and neck cancer, and colorectal cancer. In addition, PTX has shown gratifying therapeutic efficacy in heart disease, skin disease, kidney and liver fibrosis, inflammation, and acquired immunodeficiency syndrome (AIDS) (Ibrahim et al., 2002; Kinoshita et al., 2014).

Structure-activity relationship (SAR) studies of PTX have been systematically undertaken in the past three decades and are emphasized in the following sections (shown in Figure 1). Removal or 
TABLE 1 | PTX anticancer agents in clinical trials.

\begin{tabular}{|c|c|c|c|c|c|}
\hline Drug name & Formulation & Excipients & Benefit & Status & References \\
\hline Taxol & Solution & CrEL, absolute ethanol & Effective & Approved internationally & Cordell et al., 1991 \\
\hline Abraxane & $\begin{array}{l}\text { Albumin } \\
\text { nanoparticle }\end{array}$ & HSA & $\begin{array}{l}\text { Good aqueous solubility, wide scope of } \\
\text { application }\end{array}$ & Approved internationally & Park et al., 2018 \\
\hline $\mathrm{PICN}$ & $\begin{array}{l}\text { Polymeric } \\
\text { nanoparticle }\end{array}$ & $\begin{array}{l}\text { PVP, cholesteryl sulfate, } \\
\text { caprylic acid }\end{array}$ & Decreased corticosteroid pretreatment & Approved in India & Jain et al., 2016 \\
\hline DHP-107 & Emulsion & $\begin{array}{l}\text { Monoolein, tricaprylin, } \\
\text { tween } 80\end{array}$ & Oral administration & Approved in South Korea & Jang et al., 2017 \\
\hline Lipusu & Liposome & EPC, chol & No immunogenicity & Approved in China & Ye et al., 2013 \\
\hline Cynviloq & Micelle & mPEG-PDLA & $\begin{array}{l}\text { Good tolerance dose, high } \\
\text { biocompatibility }\end{array}$ & Approved in South Korea & Le et al., 2018 \\
\hline Paclical & Micelle & $\mathrm{XR}-17$ & High drug loading (1.3: 1) & $\begin{array}{l}\text { Approved in Russia, } \\
\text { Kazakhstan }\end{array}$ & Bernabeu et al., 2017 \\
\hline NK105 & Micelle & PEG-PASA & Better PSN toxicity profile than PTX. & Phase III & Fujiwara et al., 2019 \\
\hline ANG1005 & Conjugate & ANG modification & BBB-penetrating & Phase II/III & Régina et al., 2008 \\
\hline Taxoprexin & Conjugate & DHA modification & Modest activity & Phase II/III & Bedikian et al., 2011 \\
\hline Xyotax & Conjugate & PGA modification & Good aqueous solubility, less toxicity & Phase II/III & Singer, 2005 \\
\hline LEP-ETU & Liposome & $\begin{array}{l}\text { EPC, cardiolipin, Chol, } \\
\alpha-T A S\end{array}$ & Better tolerated than taxol & Phase II & Tan et al., 2006 \\
\hline EndoTAG-1 & Liposome & DOPC, DOTAP & Effective and good tolerance dose & Phase II & Christopeit et al., 2008 \\
\hline FID-007 & Micelle & PEOX & Less toxicity and better efficacy & Phase I & Yin et al., 2013 \\
\hline
\end{tabular}

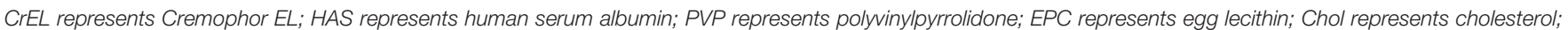

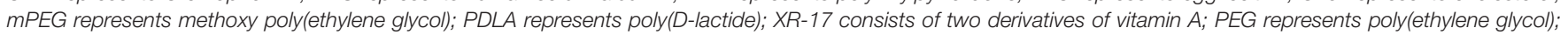

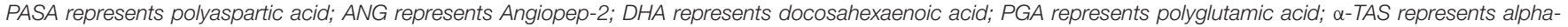

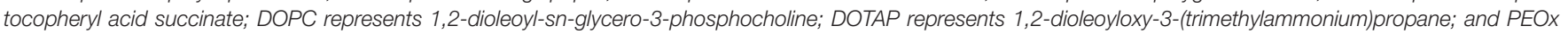
represents polyethyloxazoline.

replacement of either the hydroxyl group attached to carbon 1 (1-hydroxyl group) or the 2-acyl and 4-acyl groups of PTX reduces the bioactivity. The oxygen-containing heterocyclic ring is the pharmacophore. Notably, the 7-hydroxyl, 10-acetyl, and acetyloxy groups are the least important groups, so these regions can be further modified for multifunctional group introduction or removal. Reduction of the 9-carbonyl group leads to a slight enhancement in bioactivity. Hydroxyl or hydrolyzable ester groups should be bonded to carbon $2^{\prime}$, while phenylation or arylation requires linkage to carbon $3^{\prime}$. In addition, carbon $3^{\prime}$ must bear an amide group (Georg et al., 1992; Wahl et al., 1992; Georg and Cheruvallath, 1994; Kingston, 1994; Nicolaou et al., 1995; Gunatilaka et al., 1999). Although PTX has a bright future in chemotherapy, some inherent properties, including its poor aqueous solubility $(\leq 0.4 \mathrm{M})$, have brought about many side effects in vivo. Aiming to identify analogs with better aqueous solubility, French pharmaceutical giant Sanofi developed the second-generation antitumor agent docetaxel (DTX) in 1996, which is structurally related to PTX. Compared with PTX, hydroxyl groups instead of acetyl or acetyloxy groups were tied to carbon 10 in DTX to increase the aqueous solubility. The benzoxy group on the amide side chain adjacent to the $3^{\prime}$ carbon was converted into tert-butyl carbamate (shown in Figure 1). Additionally, the formulation of PTX commonly used in clinical settings is diluted with polyoxyethylated castor oil (Cremophor EL) in a 1:1 v/v mixture with absolute ethanol before intravenous administration. Notably, a solubilizer combination composed of polysorbate 80 and alcohol used for DTX administration has been shown to be less susceptible to producing an allergic response,

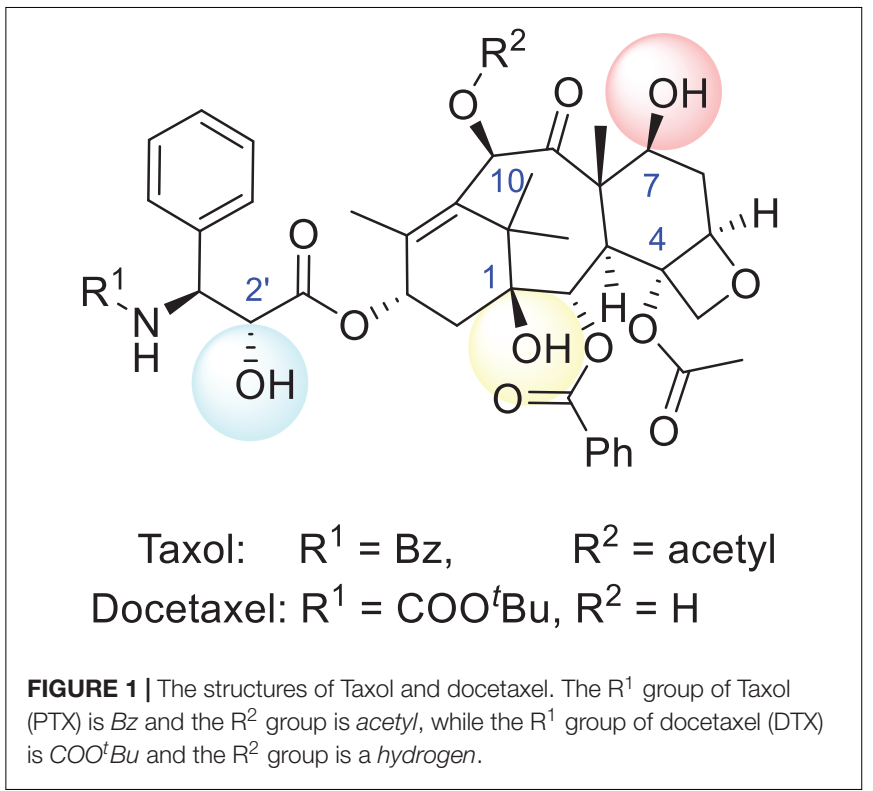

so doctors have usually tended to recommend using DTX once irritation occurs (Hanauske et al., 1992; New et al., 1996).

\section{ANTITUMOR EFFICACY OF PTX}

The first study on the anticancer activity of PTX was reported in 1971 (Wani et al., 1971), and a more in-depth study surrounding 
the anticancer mechanisms of PTX was disclosed by Schiff et al. (1979). Compared with another tubulin inhibitor, PTX inhibited the growth of cancer cells by promoting $\alpha$ - and $\beta$-tubulin subunit assembly in microtubules rather than microtubule dissociation, blocking cell cycle progression and mitosis. It was demonstrated that PTX promoted tubulin aggregation at lower critical concentrations and then activated the spindle checkpoint (mitotic checkpoint), resulting in cell division termination at either the G2 or M stage (Rowinsky et al., 1990; London and Biggins, 2014; Zierhut et al., 2019). Additionally, PTX participates in regulating cell functional responses, such as intracellular organelle transport and intracellular signaling pathways (Honore et al., 2005). For instance, the cytotoxic effects of PTX are predominantly achieved by apoptosis induction, which accelerates the production of early reactive oxygen species (ROS) and hydrogen peroxide $\left(\mathrm{H}_{2} \mathrm{O}_{2}\right)$ in cancer cells (Ramanathan et al., 2005; Alexandre et al., 2006). Alexandre and his collaborators found that after the addition of a quantitative amount of PTX to MCF-7 cells (a human breast cancer cell line), the intracellular $\mathrm{O}_{2}$ concentration did not change within $8 \mathrm{~h}$, while the extracellular $\mathrm{O}_{2}$ and $\mathrm{H}_{2} \mathrm{O}_{2}$ concentrations increased significantly. In addition, they found that PTX had a significant effect on the levels of ROS in HL-60 cells (an acute leukemia cell line) and mitochondrial defective HL-60/C6F cells (Alexandre et al., 2007). Other studies have also shown that PTX participates in regulating calcium signals and miRNA expression to induce cancer cell apoptosis and tumor therapy (Blagosklonny et al., 1997; Giannakakou et al., 2001).

Chemotherapy resistance (CR) is a major problem in cancer treatment, and, to a great extent, the cause of death from breast cancer cases can be ascribed to recurrence and metastasis (Chi et al., 2019). Long-term use of PTX might increase the odds of CR, leading to chemotherapy failure. More importantly, the underlying mechanisms of CR are still not well understood. Many possibilities have been speculated to be responsible for breast cancer resistance to PTX (Wang et al., 2014). However, overexpression of drug efflux proteins might be one of the key points. For example, excess expression of P-glycoprotein (Pgp) causes efflux pumps to extrude PTX from inside cells to the external environment, reducing PTX cytotoxicity toward cancerous cells (Wang Y. L. et al., 2018). Additionally, cancer cells can become resistant to PTX, which is possibly related to the high expression of spindle assembly checkpoint (SAC) and microtubule proteins (MAPs, such as MAP4), because the low expression of microtubules can cause the microtubules to become more fragile, making breast cancer cells more sensitive to PTX (Kavallaris, 2010). Another study showed that PTX resistance was associated with particular miRNAs. For example, a high expression of miR-200C-3P promoted breast cancer cell resistance to PTX (Khongkow et al., 2016). Therefore, the dosage of PTX recommended for individual patients was a major problem. It was reported that treatment with a low concentration (10-200 nM) of PTX inhibited the formation of the mitotic spindle, activating the mitotic checkpoint for apoptosis enhancement (Jordan et al., 1996; Sorger et al., 1997). Conversely, treatment with a higher concentration (>200 nM) of PTX damages a large number of microtubules, leading to kinase activation and apoptosis promotion (Liu and Stein, 1997; Wilson et al., 1999).

Although the use of PTX is prominent in clinical applications, some problems should not be ignored when seeking further chemotherapeutic options. PTX has extremely poor aqueous solubility, which results in low bioavailability, metabolic instability, high toxicity, and allergic reactions. Furthermore, injection of a PTX solution might result in neutropenia, bone marrow suppression, and even liver damage in many patients (Marupudi et al., 2007; Gornstein and Schwarz, 2014). Therefore, selecting the appropriate tumor-specific drug delivery method to package PTX as a prodrug or payload would reduce the side effects of PTX and improve the therapeutic outcomes to a great extent. As shown in Figure 2, common ligands, including small molecules, proteins (antibodies), aptamers, and other tumor-targeted strategies, have been introduced, and their tumor selectivity, penetration ability, circulation time, and respective limitations are described. Additionally, the linker (cleavable or non-cleavable) and payload [PTX or PTX-loaded nanoparticles (NPs)] both have a large impact on antitumor efficacy and specificity, which are mutually complementary to the therapeutic effect. In this review, comprehensive platforms for enhancing PTX specificity are discussed in detail, providing a promising outlook for PTX development in the future.

\section{SMALL MOLECULE-MEDIATED TARGETING}

The frequently used small-molecule ligands are shown in Figure 3. Due to the high affinity of ligands to their targets, small molecule-drug conjugates (SMDCs) have successfully enhanced the specificity of the cytotoxic payload toward tumors. SMDCs can distribute into tumor tissues rapidly with no immunogenicity (Srinivasarao and Low, 2017; Lee et al., 2018; Zhuang et al., 2019). In addition, SMDCs can quickly bind to the receptor and be cleared by the kidneys within $1 \mathrm{~h}$ (Srinivasarao and Low, 2017). The ligands are generally obtained by high-throughput screening, but this strategy involves a high cost and gives a low probability of success. In recent years, with the increase in DNAencoded libraries, the availability of ligands has greatly improved. Although there have been no SMDCs approved by the FDA, some of these compounds have entered preclinical or clinical trials. For example, vintafolide [a vinblastine-folic acid (FA) conjugate], developed by Merck Sharp \& Dohme Ltd. and Endocyte Ltd., failed in a phase III clinical trial, suggesting that SMDCs are still immature (Vergote and Leamon, 2015).

\section{Folic Acid (FA)}

Folic acid receptors (FARs) are overexpressed in various cancers. In addition, FA plays a vital role in DNA synthesis, repair, and cell metabolism, thus making it an ideal ligand (Marchetti et al., 2014). FA-modified poly(lactic-co-glycolic acid) (PLGA)-based NPs were shown to exhibit 3.6-fold higher cell uptake than unmodified NPs in vitro (Luiz et al., 2019). Moreover, the PTX concentration originating from FA-functionalized PTX-loaded 


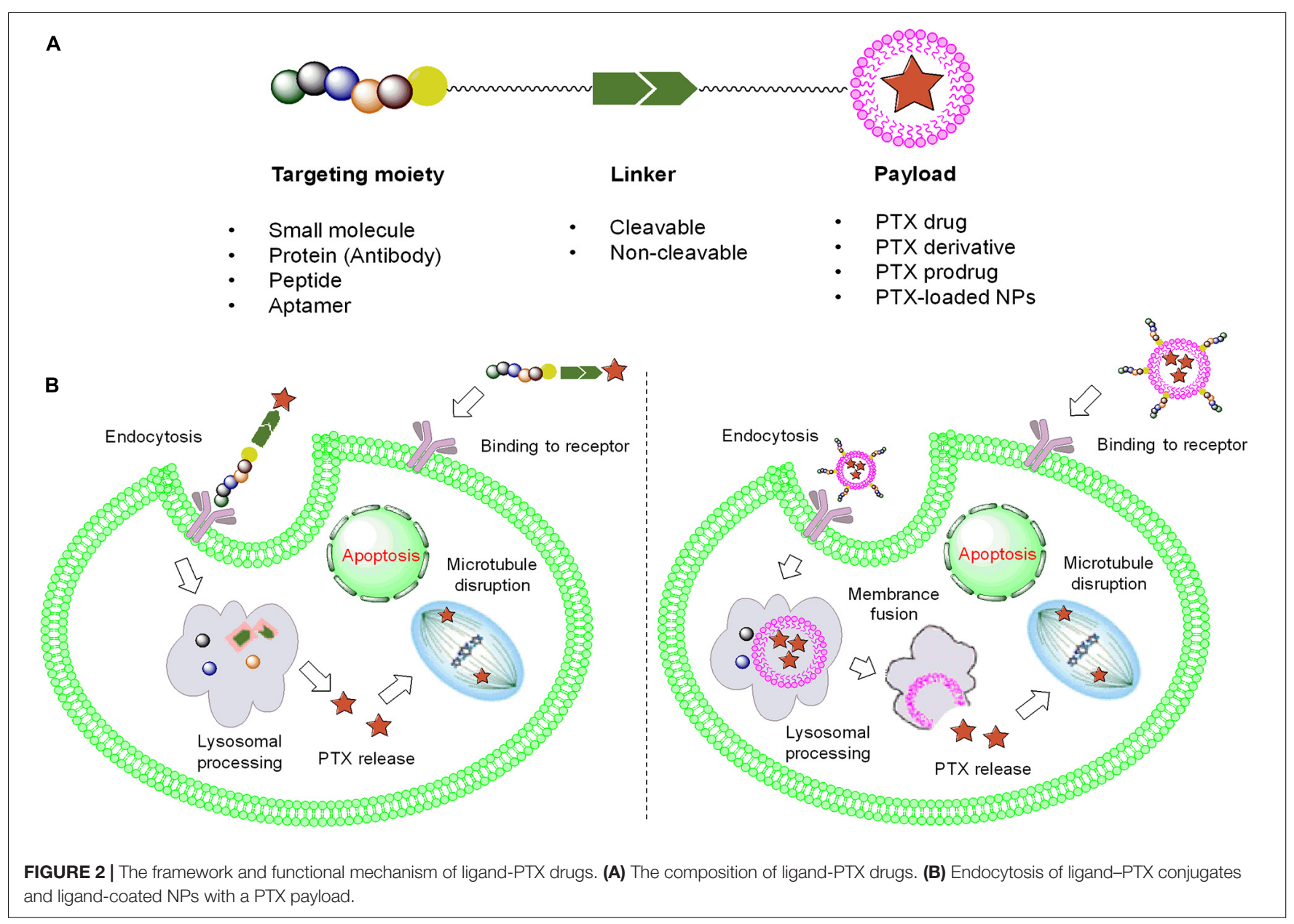

NPs (PTX-PEG-PLA-FA-NPs) was threefold higher than that of normal NPs and free PTX after SK-OV-3-bearing mice were treated with FA-NPs, NPs, and free PTX (Yao et al., 2018). Nanoformulations comprising PTX, PLGA, PEGylated octadecylquaternized lysine-chitosan (PEG-OQLCS), cholesterol, and FA showed remarkable anti-proliferative effects on HeLa cells (a human cervical cancer cell line) compared with Taxol in vitro and in vivo (Zhao et al., 2012). In addition, NPs coated with PEGylated folate sustained the enhanced permeability and retention effect (EPR), active targeting, and long circulation, while endogenous deoxycholic acid (DA) has been frequently used for adjusting the lipo-hydro partition coefficient of FA-NPs (Shen et al., 2012; Li L. et al., 2018). Combined with tumor microenvironment (TME)-responsive bonds (such as $\mathrm{pH}$, redox, and enzymatic), FA-NPs were likely to increase drug accumulation to a large extent (Puvvada et al., 2015; Fan et al., 2020). Indeed, PGA is biodegradable by cathepsin $\mathrm{B}$, which is highly expressed in tumor tissues (Decock et al., 2008).

The novel candidate PTX poliglumex $\left(\mathrm{OPAXIO}{ }^{\mathrm{TM}}\right)$ is entering phase III clinical trials to evaluate its therapeutic efficacy against ovarian cancer (Galic et al., 2011). It was found that PTX-loaded liposomes incorporated with glutamic hexapeptide-FA $\left(\mathrm{Glu}_{6}\right.$-FA) derivatives significantly affected microtubule stabilization as well as the cell cycle and cell migration (Yang et al., 2020). Aiming to improve the therapeutic efficacy, different drugs containing PTX, such as metformin (MET), doxorubicin (DOX), tariquidar (TQR), tanshinone IIA, and sorafenib, could be co-encapsulated by FA-functionalized vehicles to enhance the synergistic effects or reverse multidrug resistance (MDR) (Zhu et al., 2017; Xiao et al., 2018; Lei et al., 2019; Li et al., 2020; Zhong et al., 2020). Likewise, the combination of PTX and a photosensitizer, combining chemotherapy and photodynamic therapy, led to favorable targeting capability. PTX@FA-NLC-PEG-Ce6 nanocarriers composed of PTX, FA, and chlorin e6 (Ce6) showed great anticancer activity both in vitro and in vivo (Zhang Q. et al., 2019). In addition, various kinds of FA-coated NPs with PTX payloads, including micelles, microbubbles, nanofibers, gold NPs, gelatine-oleic NPs, nanovesicles, and graphene oxide, have been shown to enhance apoptosis induction and tumor growth inhibition (Tran et al., 2014; Wu et al., 2015; Mo et al., 2016; Luo T. et al., 2017; Liaskoni et al., 2018; Lv et al., 2018; Vinothini et al., 2019). To maximize the permeability, cell-penetrating peptides (dNP2, etc.) could also be incorporated into FA-NPs to facilitate deep penetration of the nano-formulations into glioma tumors (Li M. et al., 2018). However, a suitable FA ligand density has a significant effect on biological properties. FA-F127-PCL NPs with 


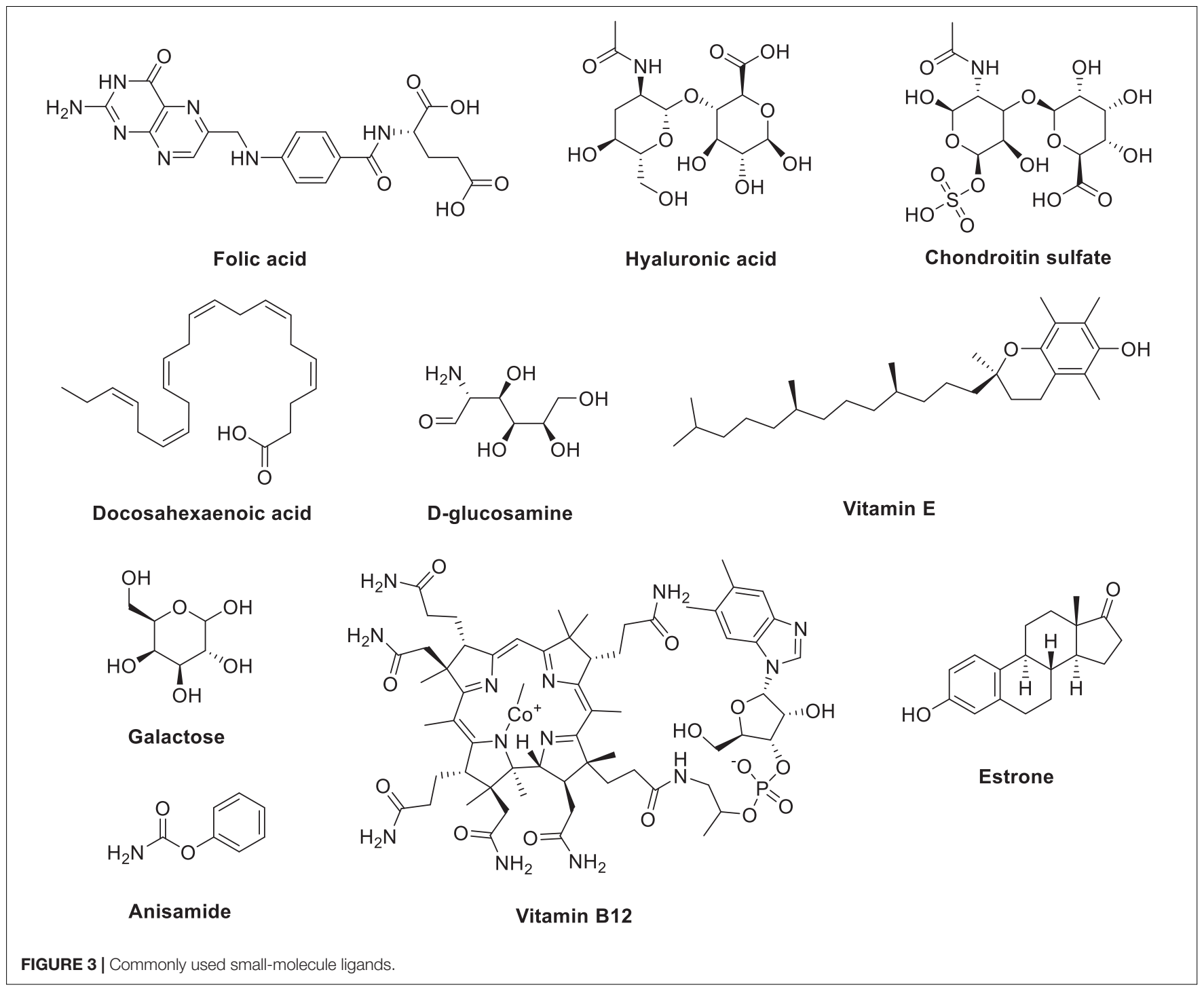

10\% FA showed superior cellular uptake and antitumor capability compared with NPs with 50 and 91\% FA (Gong et al., 2019).

\section{Hyaluronic Acid (HA) and Chondroitin Sulfate (CS)}

The CD44 receptor is often overexpressed on many malignant cancer cells (Platt and Szoka, 2008). Hyaluronic acid (HA), a widely used targeting ligand for the CD44 receptor, is inexpensive, easily conjugated, biocompatible, biodegradable, and non-immunogenic and has gained much attention worldwide (Luo et al., 2016). More importantly, HA-functionalized NPs exert a bystander effect, causing deep penetration and neighboring cell uptake in $3 \mathrm{D}$ tumor models (El-Dakdouki et al., 2013). Nano-complexes harboring composite NPs (mPPHP NPs), mPEG-PLA, and HA-conjugated PTX have exhibited preferable anticancer efficacy and tumor-targeting capabilities; moreover, a significant reduction in liver accumulation was observed compared with free
PTX (Luo et al., 2020). Biodistribution studies have shown that compared with Taxol, FA-coated PLGA NPs (PTX-HAPLGA NPs) had almost sixfold higher PTX concentrations in tumors (Wu et al., 2016). The HA-functionalized formulations (liposomes, etc.) were rapidly internalized by cancer cells. Accompanied by PTX preloading, the NPs induced strong tumor apoptosis, cellular arrest, and cytotoxic activity (Ravar et al., 2016; Su et al., 2018; Zhao et al., 2018). After activation by the TME ( $\mathrm{pH}$, redox), HA-NPs exhibited great lysosomal release and antitumor efficacy (Yin et al., 2015; Liu et al., 2016, 2020; Zhong et al., 2016; Han et al., 2019).

Anti-MDR drugs (such as apatinib) co-delivered together with PTX have shown a favorable efficacy enhancement (Zhang et al., 2020). It was found that HA-functionalized vehicles with a PTX payload notably suppressed tumor invasion, migration, and proliferation, including micelles (HA-CA), selenium NPs (HA-Se@PTX), and mesoporous hollow alumina NPs (PACHMHA) (Thomas et al., 2015; Gao et al., 2019; Zou et al., 2019; Tang Y. et al., 2020). Previous studies have shown that 
HA-coated nanostructured lipids delivering PTX remarkably prolonged blood retention and tumor accumulation compared with Taxol (Yang et al., 2013). Similar to HA, chondroitin sulfate (CS) has a high affinity for the CD44 receptor. Micelles comprising retinoic acid, CS, and PTX successfully inhibited the expression of multiple proteins associated with Golgi metastasis, angiogenesis, invasion, and tumor growth in vivo (Li et al., 2019; Zhang M. et al., 2019).

\section{Docosahexaenoic Acid (DHA)}

The Ojima group used tumor-targeting ligands such as docosahexaenoic acid (DHA), a polyunsaturated fatty acid, coupled with PTX to form DHA-PTX conjugates (shown in Figure 4). It was found that both conjugates DHA-Taxol-1 and DHA-Taxol-2 exhibited strong inhibition against DLD-1 xenografts and achieved total regression of drug-resistant and drug-sensitive tumors (Kuznetsova et al., 2006; Ojima, 2008). This group also designed fluorescently labeled redox-sensitive biotin-PTX conjugates, which were used as fluorescent probes to study the physiological and biochemical properties in biological samples and the mechanism of drug delivery through receptormediated endocytosis (RME) (Ojima et al., 2012) (shown in Figure 5A). Three years later, they introduced another two novel tumor-targeting conjugates bearing either a fluorine-labeled prosthetic as a potential 18F-positron emission tomography (PET) radiotracer or a fluorescent probe for internalization studies in a tumor-targeted drug delivery system in vitro (Vineberg et al., 2015) (shown in Figures 5B,C). Through assays, they found that in the presence of glutathione ethyl ester, only the fluorine-labeled prosthetic conjugate entered cells through the RME on the first day, exerting excellent cytotoxicity and selectivity.

\section{Glucoside-Based Molecules}

Due to the exuberant metabolism of tumor cells, glucose transporters (GLUTs) are overexpressed on the surface of cancer cells, including lung, breast, colon, esophageal, head and neck, and thyroid cancers (Smith, 1999). Therefore, glucose is also able to act as a tumor-targeting ligand. It was found that Dglucosamine-functionalized copolymer NPs encapsulating PTX (DGlu-NP/PTX) exhibited more favorable anticancer ability and specificity than Taxol NPs and plain NPs without evident toxicity in vitro and in vivo (Jiang et al., 2014). In addition, the vast majority of the asialoglycoprotein receptor (ASGP-R) is expressed on the cellular membrane of hepatocytes and has often emerged as a specific target for hepatocellular carcinoma (Borker and Pokharkar, 2018). Owing to its multi-antennary galactose modification, these functionalized NPs were capable of binding to ASGP-R with an increased dissociation constant $\left(\mathrm{K}_{\mathrm{d}}\right)$. Thus, galactose-functionalized PTX-loaded gold NPs (Gal/PTXGNPs) showed a considerable enhancement in anti-proliferative activity in HepG2 cells (a human hepatoma cell line) with little hepatotoxicity (Gao et al., 2017).

\section{Vitamin-Based Molecules}

The overexpression of P-gp, an ATP-binding cassette transporter that pumps hydrophobic molecules out of the cell through the cellular membrane, is a key factor in MDR development (Amawi et al., 2019). D- $\alpha$-Tocopheryl PEG-1000 succinate (TPGS), which is an amphipathic vitamin E (VE) derivative, has been considered an efficient P-gp inhibitor and is widely used for chemotherapeutic delivery (Collnot et al., 2010). NPs containing PTX and TPGS have been used for the treatment of various cancers, including lung, breast, colorectal, brain, and prostate cancer, among others (Gorain et al., 2018).

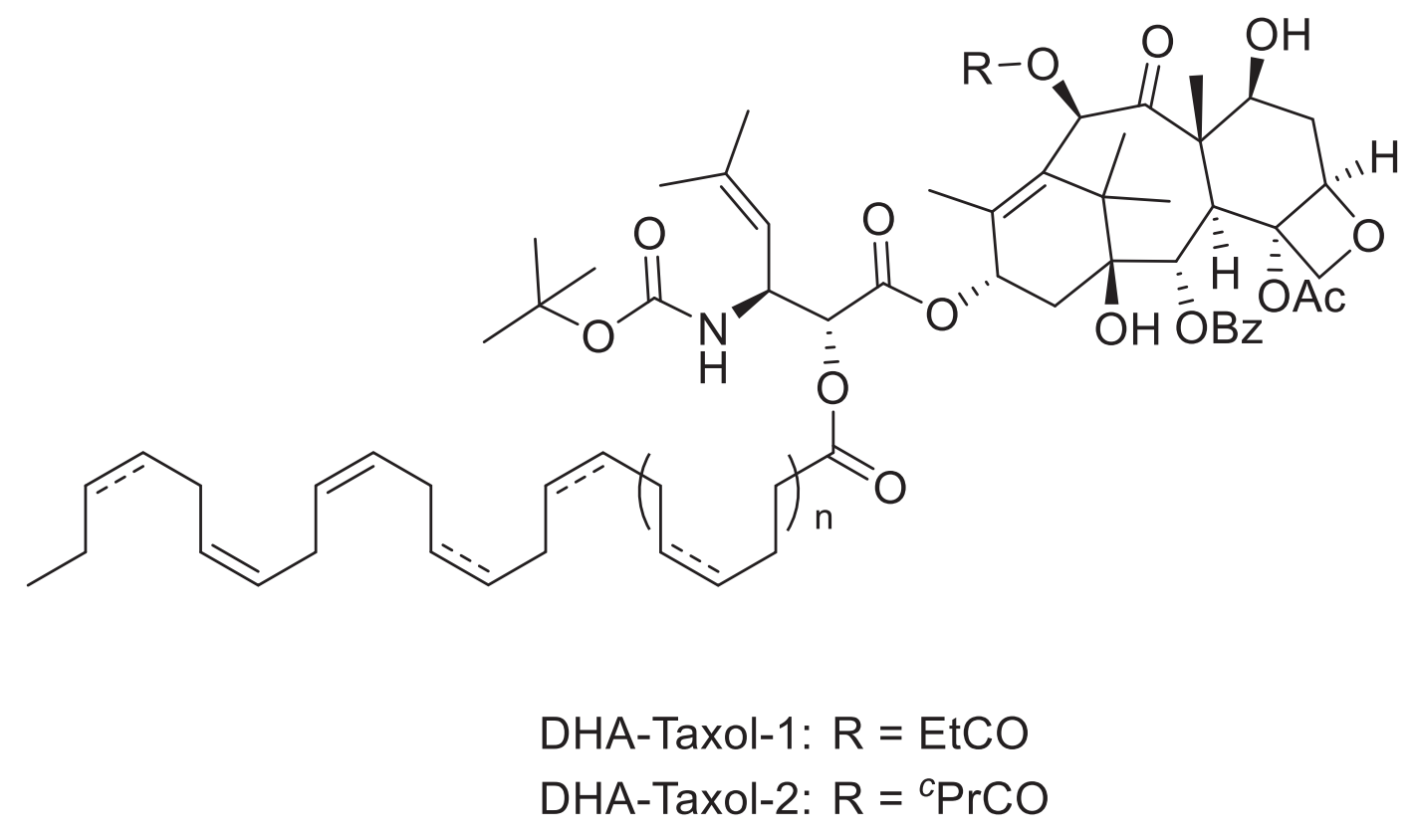

FIGURE 4 | The structures of two DHA-PTX conjugates. 


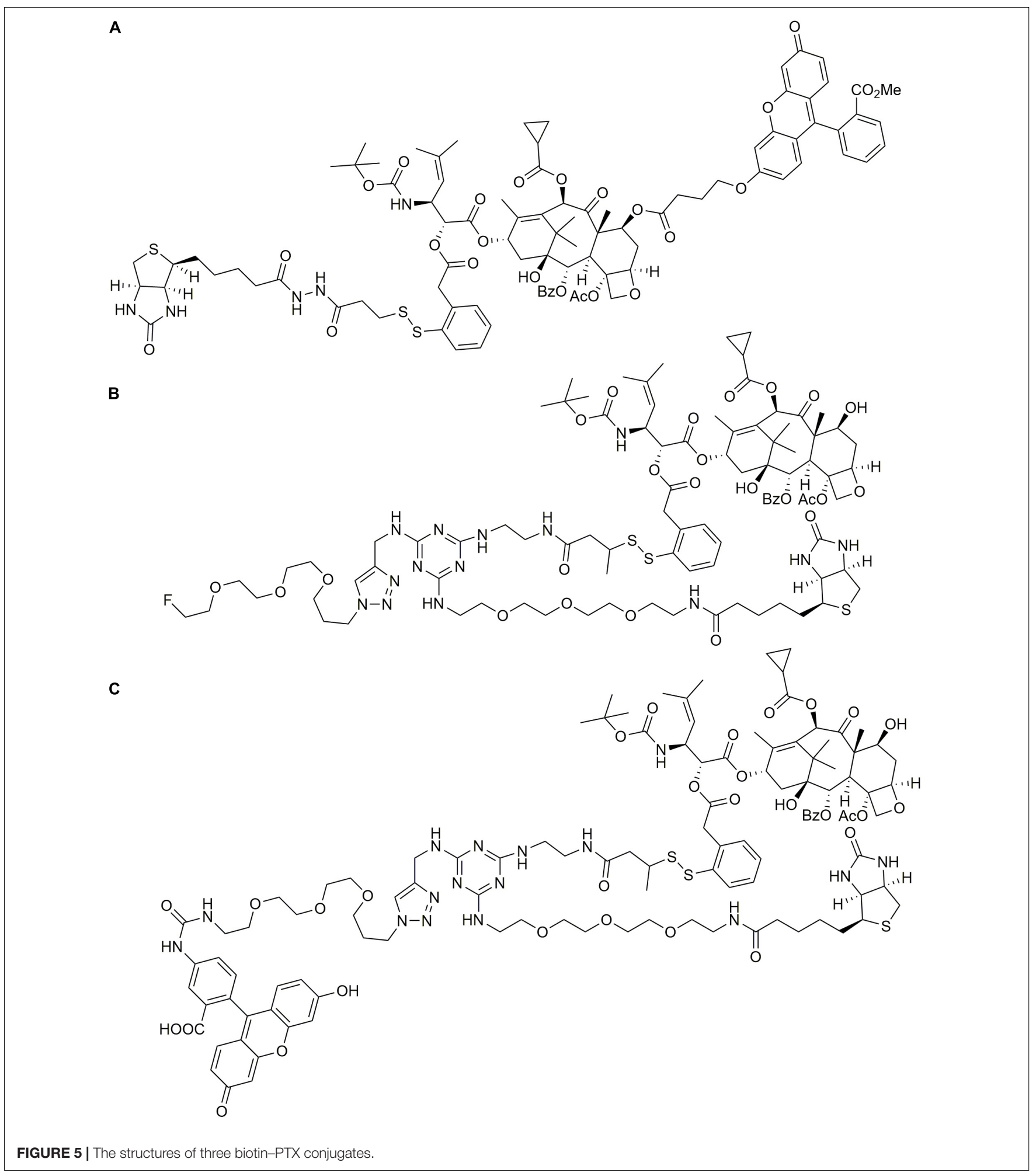

For instance, it was found that 9-fluorenylmethyloxycarbonyl (Fmoc)-modified VE showed a strong interaction with PTX. Moreover, VE-based micelles $\left(\mathrm{PEG}_{5 \mathrm{~K}}-\mathrm{VE}_{2}\right)$ encapsulating PTX exerted superior antitumor abilities with minimal adverse effects (Zhang et al., 2014). Due to the high expression of the CD320 receptor (CD320-R) in many cancers, vitamin B12 (VB12, a CD320-R ligand) is also frequently used in tumor-targeting therapy (Arora et al., 2017). Guo et al. (2019) demonstrated that VB12-sericin micelles with a PTX payload effectively penetrated tumor cells via CD320-R-mediated endocytosis to 
alter the mitochondrial transmembrane potential and cause tumor apoptosis activation.

\section{Other Small Molecules}

Tenascin-C (TN-C), an extracellular matrix (ECM) glycoprotein, is highly expressed in various cancer cells, including ovarian, breast, and prostate cancer (Chiquet-Ehrismann and Chiquet, 2003). Sulfatide, an acidic sphingosaccharide that is partially sulfated, has a high affinity for TN-C. It was revealed that sulfatide-coated lipid perfluorooctylbromide NPs harboring PTX (PTX-SNPs) could prolong retention and accumulation, resulting in better tumor suppression than free PTX and nonspecific NPs (Li et al., 2014). Likewise, alendronate (ALN) exhibits excellent bone-targeting abilities and is often adopted as an osteosarcoma ligand. ALN-grafted PTX-containing NPs displayed good cytotoxicity and tumor accumulation, resulting in preferable therapeutic efficacy over Taxol (Zhao et al., 2019).

In addition, the sigma- 1 receptor, which is a membranebinding protein that is highly expressed in human prostate tumors, is essential for prostate cancer cell survival and growth (Urandur et al., 2018). Anisamide has a high affinity for the sigma-1 receptor, which makes it a suitable ligand for prostate cancer treatment. It was revealed that amphiphilic micelles composed of PTX, anisamide, and $\mathrm{N}$-octyl-N,O-maleoyl-Ophosphoryl chitosan (PTX-aM) could be triggered by low $\mathrm{pH}$ to increase cellular internalization and tumor accumulation and promote survival of PC-3 (human prostate carcinoma cell line)bearing mice (Qu et al., 2020). Moreover, the estrogen receptor (ER) has a significant effect on the female endometrium, ovary, and breast, and upregulation of the ER has been observed in these tumor tissues (Borrow and Handa, 2017). Thus, estrone (ES), an estrogen, enables binding to the ER, wherein co-delivery of PTX and epirubicin was performed employing ES-functionalized liposomes. This nano-formulation exhibited increased systemic circulation and tumor growth suppression without evident toxicity (Tang H. et al., 2020).

\section{PROTEIN-MEDIATED TARGETING}

\section{Albumin}

Albumin is an endogenic serum protein. It accounts for over $60 \%$ of the total proteins in plasma and plays a very important role in various physiological functions (Jupin et al., 2013). Human serum albumin (HSA) has a preferential affinity for hydrophobic moieties and also shows biocompatibility, and thus, it has been exploited as a perfect delivery system for drug transportation. NP albumin-bound PTX (nab-PTX, Abraxane) is becoming the most important targeted chemotherapeutic drug for many types of cancer treatments. One kind of $60-\mathrm{kDa}$ sialoglycoprotein (gp60) and secreted protein acidic and rich in cysteine (SPARC), an albumin receptor, are highly expressed on the surface of endothelial cells and cancer cells, respectively (Iglesias, 2009; Zhu et al., 2016). As shown in Figure 6, nab-PTX could first recognize gp60 in the endothelia and then activate the caveolin-1 process. After transportation into the tumor interstitium via the caveolaemediated pathway, nab-PTX could bind to SPARC, facilitating

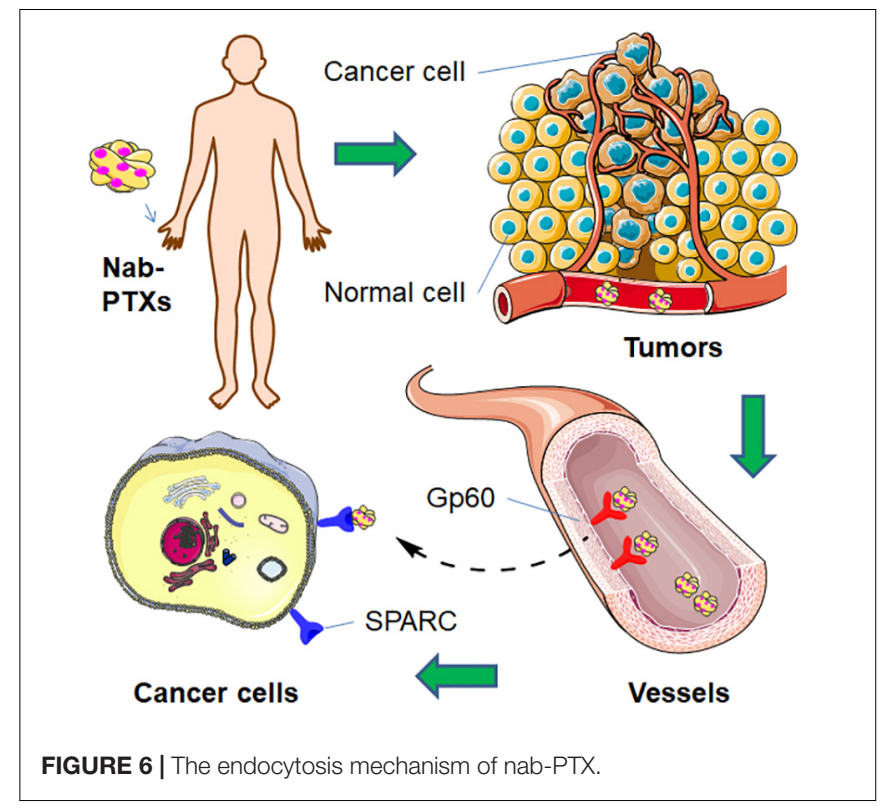

the release of PTX around cancer tissues and improving the anticancer effects (Abu Samaan et al., 2019).

\section{Antibodies}

Although some considerable progress has been devoted to SMDCs, their binding affinity is often questioned, causing non-negligible toxicity owing to off-target effects. Antibodies, known as immunoglobulins, are large Y-shaped proteins mainly secreted by plasmocytes that play roles in the immune system to identify and neutralize pathogens such as bacteria and viruses. Antibodies exist in the plasma of vertebrates and on the surface of the B cell membrane (Litman et al., 1993). One characteristic of antibodies is that they can recognize antigens via the fragment antigen-binding (Fab) variable region, which has derived many antibody-type anticancer drugs evaluated from this aspect. It has been more than 100 years since the discovery of antibodies in the 1880s, and they have become popular worldwide. With the advent of humanized antibodies and bispecific antibodies, functional monoclonal antibodies have also become increasingly successful (Husain and Ellerman, 2018; Baker et al., 2020). After the worldwide COVID-19 outbreak, antibodies have become potential drug candidates for its treatment. Antibodies are capable of inhibiting coronavirus activity and protecting cells from damage by binding to this virus (Marovich et al., 2020). However, the administration of a single antibody often fails in cancer therapy. Antibody-drug conjugates (ADCs) perfectly combine monoclonal antibodies with an effective cytotoxic payload, making full use of the specific binding ability to the target of the former and overcoming defects such as the low efficacy of the former and the large side effects of the latter. ADCs usually consist of three components: an antibody, a linker, and a cytotoxin. The antibody guides the ADC, which can deliver the payload to cancer cells in a targeted way. The linker regulates the pharmacokinetics and pharmacodynamics of the conjugate by altering the polarity of 

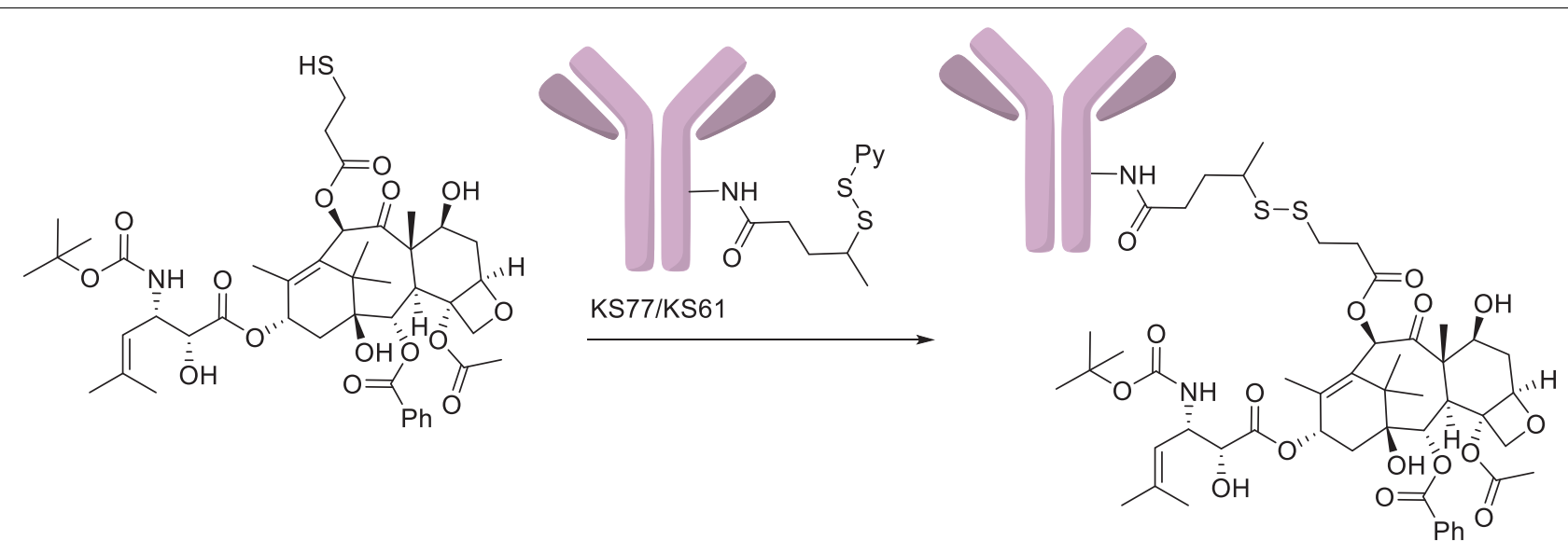

KS77-taxoid/KS61-taxoid

FIGURE 7 | The KS77/KS61-PTX conjugates (Ojima et al., 2002).

the molecule. With these components, ADCs can effectively penetrate tumors by specific binding to antigens and then endocytose into cancer cells.

Paclitaxel, as a natural anticancer drug, bears great expectations for clinical applications, but its drawbacks, such as poor solubility and lack of tumor selectivity, are very prominent. Conversely, antibodies had low therapeutic efficacy but high aqueous solubility and excellent tumor target selectivity in cancer cells. Therefore, antibody-PTX conjugates appear to be a better choice for therapeutic applications that can garner the benefits of the two monomers. One of the earliest studies on antibody-PTX conjugates was by Guillemard and Saragovi (2001), who found that several PTX-antibody conjugates have high aqueous solubility, excellent tumor target selectivity, and high therapeutic efficacy, affording more cytotoxicity than free PTX or a mixture of free PTX and the free antibody in vitro. In addition, the PTX-ADCs prevented the growth of tumors and prolonged the survival of mice to a greater extent than free PTX. Ojima et al. (2002) used a disulfide linker to conjugate a PTX derivative and the antibody KS77 or KS61 (shown in Figure 7), which was specifically targeted to the epidermal growth factor receptor (EGFR). PTX-ADC was found to clearly prevent the growth of A-431 xenografts in SCID mice, whereas free PTX did not show any efficacy (similar to the blank sample) (shown in Figure 8). In 2010, the Safavy group designed a high drug-loaded completely soluble antibody-PTX conjugate linked with a discrete poly(ethylene glycol) (dPEG) for tumor-targeted chemotherapy. Through their experiments, they found that the conjugates remained homogeneous for a long time. The immunogenicity of these conjugates was also preserved via fluorescence-activated cell sorting (FACS) analysis compared with the sample without antibody. In addition, bioactivity studies in MDA-MB-468 cells (a human breast cancer cell line) proved that drug cytotoxicity was preserved (Quiles et al., 2010). This work provided a basis for further studies on antibody-PTX conjugates (Yao et al., 2016).

\section{APTAMER-MEDIATED TARGETING}

Aptamers, generated from the systematic evolution of ligands by exponential enrichment (SELEX) selection process, are three-dimensional structures of a single-stranded DNA or RNA oligonucleotide sequence with a short length of 20100 bases and are considered to be monoclonal antibody mimics. Due to diversely combined sequences, these kinds of short oligonucleotides could form in unnumbered spatial conformations; thus, all aptamers interacting with target substances could be simulated and determined (Kong and Byun, 2013; Sun et al., 2016). SELEX has gradually become a hotspot in the research and development of biomaterials (Ni et al., 2020). Compared with monoclonal antibodies, aptamers have unique internal strengths, mainly as follows: high aqueous solubility, high stability, versatile modifications, high specific target binding affinity, ease of synthesis in vitro with no batch-to-batch variation, a low manufacturing cost, and low immunogenicity and toxicity. Since they are relatively quickly filtered by the kidney, general protocols for instillation of longacting modifications have usually been carried out by chemical reactions to introduce macromolecules such as PEG to improve their renal threshold and half-life. Aptamers are used both alone for tumor treatment and as aptamer-drug conjugates (ApDCs) (Bouchard et al., 2010).

\section{AS1411}

Nucleolin is located in the cell nucleus in normal cells, while immanent overexpression of nucleolin on the surface of various cancer cells has been observed (Abdelmohsen and Gorospe, 2012). AS1411 is a G-quadruplex-based aptamer that has been evaluated for its antitumor ability in phase II clinical trials (Rosenberg et al., 2014). This aptamer has shown favorable tumor specificity and biological compatibility and has been widely used in different drug delivery platforms. In addition, AS1411 itself has the potential to inhibit tumor-associated protein activity and may even be active in cell survival, 


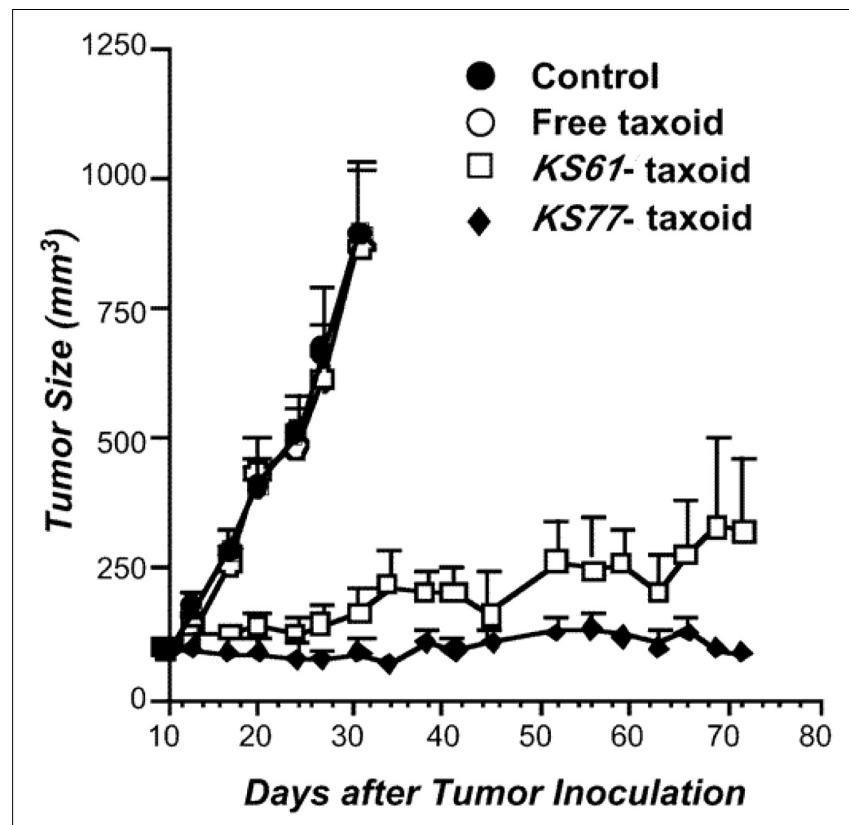

FIGURE 8 | Antitumor activity of the KS77/KS61-PTX conjugates against A-431 xenografts in SCID mice (Ojima et al., 2002).

growth, proliferation, nuclear transport, and transcription (Mongelard and Bouvet, 2010). Once AS1411 recognizes the targeted cell surface marker, the conjugates can penetrate the cells by endocytosis, and then the linker is cleaved, resulting in the release of the payload to the target site (Oh et al., 2014).

In 2017, Zhang's group conjugated the nucleolar aptamer and PTX with a stable cathepsin B-sensitive dipeptide linker to form an aptamer-PTX conjugate with high aqueous solubility, prodrug transmittability, and tumor inhibition (shown in Figures 9, 10), which gathered target-specific binding affinity derived from the aptamer and cytotoxicity generated by PTX. These ApDCs adopted a stable enzyme-cleavable dipeptide linker that prevented the side effects generated by PTX through off-target effects from normal cells. Only when cancer cells were recognized by the aptamer part of ApDCs could this drug enter the cell by endocytosis, and then the linker could be degraded by cathepsin B, resulting in the release of payload to the target site. Through experiments, they found that ApDCs afforded higher therapeutic efficacy and prevented the growth of mouse xenografted tumors compared with free PTX or the free aptamer in vitro, which demonstrated the anticancer ability of ApDCs to perform robustly and accurately (Li F. et al., 2017). Correspondingly, AS1411 incorporated into PTX-harboring NPs has frequently been used for antitumor therapeutic exploitation. For instance, Luo and collaborators described that AS1411-modified poly(L$\gamma$-glutamyl-glutamine) nanoconjugates encapsulating PTX (AS1411-PGG-PTX) significantly increased cellular uptake, apoptosis, and anti-proliferative activity in U87MG cells (a human glioblastoma cell line). These NPs significantly increased tumor accumulation and extended the median survival time in glioma-bearing mice (Luo Z. et al., 2017). In addition, AS1411-coated PTX-loaded NPs (Apt-PTXPLGA NPs) gathered benefits against glial cancer cells, with little impact on normal mammary epithelial cells. Aravind and his collaborators found high cellular uptake after GI-1 cells (a human glial cancer cell line) were treated with Apt-PTX-PLGA NPs in contrast to uncoated NPs. Visible retention, internalization, and tumor accumulation were observed in vitro and in vivo (Aravind et al., 2012). Additionally, it was demonstrated that AS1411-endowed HSA NPs carrying PTX (Apt-NPs-PTX) exerted preferential penetration via nucleolin-mediated endocytosis, resulting in increased anti-proliferative activity against MCF-7 cells, contrary to MCF-10A cells (a normal human breast cell line), which were barely affected ( $\mathrm{Wu}$ et al., 2013). The combination of PLK1-targeted siRNA and AS1411-modified liposomes co-harboring PTX caused improved tumor cell apoptosis and anti-angiogenic efficacy in vitro and in vivo (Yu et al., 2019).

\section{Other Tumor-Targeted Aptamers}

As mentioned above, PD-L1, MUC1, and heparin sulfate are upregulated in many cancers. In 2020, Zhang's group developed a new PD-L1 aptamer-PTX conjugate that enhanced the antiproliferative efficacy in $\mathrm{PD}-\mathrm{L} 1$-overexpressing triple-negative breast cancer cells (Wu et al., 2020). In addition, Mie and colleagues designed novel targeting nanocomposites of elastinlike polypeptides, poly-aspartic acid, PTX, and MUC1-binding aptamers. These NPs displayed enhanced cytotoxicity to MCF7 cells compared with non-targeted NPs (Mie et al., 2019). It was reported that a MUC1 aptamer conjugated to either PLGA NPs or chitosan-coated HSA with PTX encapsulation significantly increased the transmittability toward MCF-7 cells and T47D cells (a human mammary ductal carcinoma cell line) (Yu et al., 2011; Esfandyari-Manesh et al., 2016). HPA, which is highly expressed in human tumors, is responsible for heparin sulfate degradation. It has been proven that the S1.5 aptamer specifically binds to HPA (Silva et al., 2013). Therefore, S1.5decorated PEG-PLGA micelles with a PTX payload [Apt(S1.5)PTX-NP] exhibited favorable cellular uptake and cytotoxicity enhancement in MDA-MB-231 cells (a human breast cancer cell line) in comparison with plain micelles. In addition, $\mathrm{Apt}(\mathrm{S} 1.5)$ PTX-NP significantly increased the anti-angiogenesis and antiinvasive effects, resulting in the most effective therapeutic efficacy (Duan et al., 2019).

Platelet-derived growth factor receptor $\beta$ (PDGFR $\beta$ ) is overexpressed in glioma and is involved in tumor angiogenesis, migration, and proliferation. It was found that the Gint4.T aptamer could tightly bind to PDGFR $\beta$ and transport across the blood-brain barrier (BBB), which is suitable for drug delivery to the brain (Delac et al., 2015; Monaco et al., 2017). Combined with glioma-targeting aptamer GMT8, dualfunctionalized tetrahedral framework oligonucleotides carrying PTX were capable of inhibiting the migration, invasion, and proliferation toward U87MG cells, resulting in cancerous apoptosis enhancement (Shi et al., 2019). Additionally, Sun 


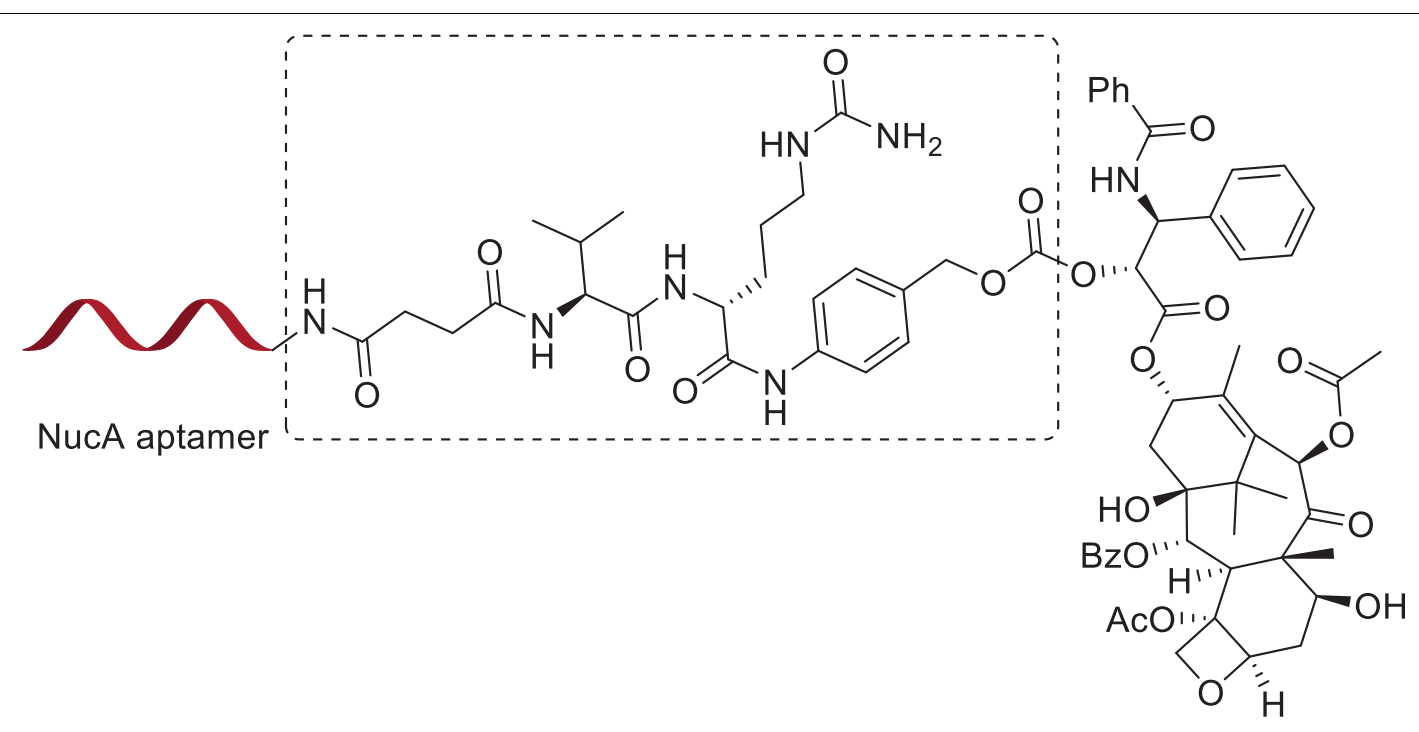

FIGURE 9 | The structure of the NucA-PTX conjugate.

FIGURE 10 | The aqueous solubility of free PTX and the NucA-PTX conjugate. The scale bar indicated is $3 \mathrm{~mm}$. Copyright from Zhang et al. (Li F. et al., 2017).

and collaborators demonstrated that RNA aptamers served as an effective tool against $\mathrm{CD}_{133^{+}}$cells. The targeted NP codelivery of PTX and surviving siRNA (DP-CLPs-PTX-siRNA) resulted in selective apoptosis and tumorigenesis inhibition, leading to extended survival rates of glioma-bearing nude mice (Sun et al., 2018).

Non-small-cell lung cancer (NSCLC) represents a predominant class (>80\%) of lung cancers, leading to significant cancer-related death worldwide. By virtue of SELEX technology, a novel aptamer (S15-APT) was developed, which exerted favorable affinity and specificity for NSCLC (Zhao et al., 2009). When S15-APT was incorporated into PTX-loaded NPs, an increased inhibitory rate was observed in various cancer cell lines compared with free PTX, including in HeLa cells, BEAS2B cells (a human bronchial epithelial cell line), and Caco-2 cells (a human colorectal adenocarcinoma cell line) (Engelberg et al., 2019). For prostate cancer with specific membrane antigen (PSMA) expression, A10-3.2 aptamer-functionalized PLGA-based nanobubbles delivering PTX (PTX-A10-3.2-PLGA NBs) showed high selectivity toward LNCaP cells (a human prostate cancer cell line). With the help of ultrasound, it was confirmed that these NBs achieved prominent tumor inhibition and increased median survival time without notable toxicity (Wu et al., 2017).

\section{OTHER TUMOR-TARGETING STRATEGIES}

\section{Magnetic Iron Oxide-Mediated Targeting}

Magnetic NPs have been widely applied in the realm of cancer therapy owing to their physical properties and biocompatibility (Xie et al., 2010). It was reported that PTX loaded into poly(ethylene glycol) carboxyl-poly( $\varepsilon$-caprolactone) magnetic NPs (PEG-PCCL-MNP/PTX) induced excellent therapeutic ability with low phlebitis and hemolysis ( $\mathrm{Li} \mathrm{X}$. et al., 2017). NPs composed of PTX and PEGylated PLGAbased superparamagnetic iron oxide NPs (PTX/SPIO-NPs) significantly enhanced the median survival time of glioblastomabearing mice (Ganipineni et al., 2018). Likewise, multifunctional magnetic NPs carrying PTX, SPIO, and Pluronic F127 suppressed tumor growth and prolonged the survival time of colon cancerbearing mice (Dehvari et al., 2016). Combined with the pH-stimulating peptide $\mathrm{H}_{7} \mathrm{~K}\left(\mathrm{R}_{2}\right)_{2}$, SPIO-based liposomes 
containing PTX [PTX/SPIO-SSL- $\mathrm{H}_{7} \mathrm{~K}\left(\mathrm{R}_{2}\right)_{2}$ ] confirmed a good therapeutic effect on MDA-MB-231 cells in vitro and in vivo (Zheng et al., 2018).

\section{Biomembrane-Mediated Targeting}

When PTX is coated with immune or cancer cell membranes, this drug has a fake identity to escape the clearance system and home to tumor regions. After pre-priming, engineered mesenchymal stem cells (MSCs) carrying PTX can release the drug package by secreting membrane microvesicles (MVs) into tumors for several days (Pascucci et al., 2014; Layek et al., 2018). In addition, cancer cells can produce extracellular vesicles (EVs), which are often used for delivery systems. It was demonstrated that lung cancer cell-derived EVs with the oncolytic virus and PTX payload importantly targeted the neoplasia and triggered inflammatory reactions (Garofalo et al., 2019). Additionally, E7-targeting siRNA and PTX co-loaded PLGA NPs camouflaged with HeLa cell membranes exhibited threefold higher accumulation than normal NPs in tumors. Clear synergistic anticancer abilities were observed, and the tumor volume ranges were reduced by almost 83.6\% (Xu et al., 2020).

\section{DISCUSSION AND FUTURE PERSPECTIVES}

Since its discovery in the 1960s, PTX has become one of the most widely used chemotherapeutics throughout the world. Although 50 years has passed, the tremendous market of PTX, which has been a clinical and financial success, still attracts numerous pharmaceutical companies and scientists. Due to its poor solubility and severe adverse effects, such as hematotoxicity, neurovirulence, and gastrointestinal disorders, much effort has been made to overcome the drawbacks associated with its clinical application. Enhancing the tumor specificity of PTX is an effective solution to overcome these barriers. Currently, there have been many pathways that have achieved high affinity and specificity of PTX to tumors, mainly ligandreceptor-mediated targeting, cancer cell homing, and physics (superparamagnetism)-mediated guidance. Therefore, ligandreceptor-mediated active targeting has been studied in depth, and substantial progress has been made. According to the type of ligand (small molecules, antibodies, and aptamers) and payload (PTX and PTX-loaded NPs), tumor-specific PTX drugs can be simply classified into small-molecule-PTX (drug) conjugates (SMDCs), antibody-PTX conjugates (ADCs), aptamer-PTX conjugates (ApDCs), and ligand-functionalized PTX-loaded NPs.

In general, all ligand-PTX drugs consist of cytotoxic payloads, linkers, and tumor-targeting moieties. In recent decades, PTX SAR studies have been systematically undertaken and fully understood. The inactive groups could be either replaced for solubility improvement (DTX) or derivatized for targetingmoiety conjugation. At this point, ligand-PTX drugs have been enabled to sustain antitumor efficacy, and the cytotoxic payload does not have to be cleaved from the ligand, whereas high tumor specificity plays a vital role. On the other hand, modification of active sites would generate PTX prodrugs, which have minimized side effects on normal cells and tissues (Wang G. et al., 2018). However, the complete removal of modified groups has greatly contributed to PTX activation, emphasizing the importance of tumor sensitivity. Linkers can be mainly divided into cleavable and non-cleavable types. Particularly in ADCs, it is necessary to evaluate the residual effects when using non-cleavable linkers. TME-responsive linkers are frequently applied as connecting arms, accompanied by self-immolative spacers (Mccombs and Owen, 2015). When ligand-PTX drugs accumulate in tumors, the linkers are triggered by various stimulants in the TME and degraded. Afterward, self-immolative spacers can facilitate the release of PTX, resulting in an effective antitumor outcome. Thus, high tumor selectivity resulting from ligands is a critical point for therapeutic improvement.

Notwithstanding the capabilities of small molecules, antibodies, and aptamers toward tumor cells, these molecules have individual advantages and disadvantages. Small molecules have been adopted as tumor-specific ligands and exhibit great stability, rapid biodistribution, and high penetration abilities. However, their simple structures and low molecular weights (LMWs) often lead to inferior tumor specificity and kidney filtration compared with antibodies. Despite ADC succession on the market, inherent shortcomings, including instability, timeconsuming preparation ( $>6$ months), high immunogenicity, and manufacturing cost, significantly restrict the widespread use of antibodies. In contrast, aptamers composed of three-dimensional single-stranded oligonucleotides possess superior stability, easy synthesis and modification, high affinity and specificity, and low immunogenicity. More importantly, it is easy to screen specific ligands for a variety of targets utilizing SELEX technology. Recently, SELEX has become a hotspot for the recognition of undruggable targets. With the rapid development of screening processes, the new generation of SELEX relying on highthroughput sequencing, capillary electrophoresis, microfluidic chips, fluorescent magnetic beads, and so on has significantly reduced the selection periods (converted from 8-20 to 4 cycles), which provides bright prospects for individualized PTX-based treatment (Mendonsa and Bowser, 2005; Stoltenburg et al., 2005; Kim, 2011; Dupont et al., 2015).

According to current PTX applications in the clinic, it has been reasonably hypothesized that individual differences significantly affect the therapeutic efficacy and side effects among patients. Under transcriptomics and proteomics, it is easy to know whether CR-associated genes (such as P-gp) are highly expressed, affording a guideline for individual PTX-based therapy. Moreover, the burgeoning SELEX technology makes it possible to select personalized aptamers for each patient. It has been reported that primary cancerous cells and biopsies directly originating from patients have been used for individual tumor-specific aptamer selection (Liu et al., 2019; Takakura et al., 2019; Zamay et al., 2019). Additionally, organoid technology has become one of the most important breakthroughs, so patientderived tumoroid-based SELEX is likely to exhibit exciting potential prospects for personalized ApDC treatment. Moreover, neoantigens caused by genetic mutations are perfect targets because of their existence only in tumors. Combining DNA/RNA sequencing, computational simulations, artificial intelligence, 
and SELEX technologies, complete tumor-specific aptamers are likely to be obtained. A novel ApDC composed of a specialized aptamer and PTX is expected to eliminate off-target effects and significantly improve the therapeutic efficacy in patients with cancer.

\section{AUTHOR CONTRIBUTIONS}

YM and SY wrote the manuscript. SN, BZ, AK, and JG helped in revising the manuscript. AL and GZ proposed constructive discussions and supervised the manuscript. All authors contributed to the article and approved the submitted version.

\section{REFERENCES}

Abdelmohsen, K., and Gorospe, M. (2012). RNA-binding protein nucleolin in disease. RNA Biol. 9, 799-808. doi: 10.4161/rna.19718

Abu Samaan, T. M., Samec, M., Liskova, A., Kubatka, P., and Busselberg, D. (2019). Paclitaxel's mechanistic and clinical effects on breast cancer. Biomolecules 9:789. doi: 10.3390/biom9120789

Alexandre, J., Hu, Y. M., Lu, W. Q., Pelicano, H., and Huang, P. (2007). Novel action of paclitaxel against cancer cells: bystander effect mediated by reactive oxygen species. Cancer Res. 67, 3512-3517. doi: 10.1158/0008-5472.CAN-063914

Alexandre, J., Nicco, C., Chereau, C., Laurent, A., Weill, B., Goldwasser, F., et al. (2006). Improvement of the therapeutic index of anticancer drugs by the superoxide dismutase mimic mangafodipir. J. Natl. Cancer Inst. 98, 236-244. doi: $10.1093 /$ jnci/djj049

Amawi, H., Sim, H. M., Tiwari, A. K., Ambudkar, S. V., and Shukla, S. (2019). ABC transporter-mediated multidrug-resistant cancer. Adv. Exp. Med. Biol. 1141, 549-580. doi: 10.1007/978-981-13-7647-4_12

Aravind, A., Varghese, S. H., Veeranarayanan, S., Mathew, A., Nagaoka, Y., Iwai, S., et al. (2012). Aptamer-labeled PLGA nanoparticles for targeting cancer cells. Cancer Nanotechnol. 3, 1-12. doi: 10.1007/s12645-011-0024-6

Arora, K., Sequeira, J. M., and Quadros, E. V. (2017). Maternofetal transport of vitamin B12: role of TCblR/CD320 and megalin. FASEB J. 31, 3098-3106. doi: 10.1096/fj.201700025R

Baker, D., Ali, L., Saxena, G., Pryce, G., Jones, M., Schmierer, K., et al. (2020). The irony of humanization: alemtuzumab, the first, but one of the most immunogenic, humanized monoclonal antibodies. Front. Immunol. 11:124. doi: 10.3389/Fimmu.2020.00124

Bedikian, A. Y., Deconti, R. C., Conry, R., Agarwala, S., Papadopoulos, N., Kim, K. B., et al. (2011). Phase 3 study of docosahexaenoic acid-paclitaxel versus dacarbazine in patients with metastatic malignant melanoma. Ann. Oncol. 22, 787-793. doi: 10.1093/annonc/mdq438

Bernabeu, E., Cagel, M., Lagomarsino, E., Moretton, M., and Chiappetta, D. A. (2017). Paclitaxel: what has been done and the challenges remain ahead. Int. J. Pharmaceut. 526, 474-495. doi: 10.1016/j.ijpharm.2017. 05.016

Blagosklonny, M. V., Giannakakou, P., Eldeiry, W. S., Kingston, D. G. I., Higgs, P. I., Neckers, L., et al. (1997). Raf-1/bcl-2 phosphorylation: a step from microtubule damage to cell death. Cancer Res. 57, 130-135.

Borker, S., and Pokharkar, V. (2018). Engineering of pectin-capped gold nanoparticles for delivery of doxorubicin to hepatocarcinoma cells: an insight into mechanism of cellular uptake. Artif. Cells Nanomed. Biotechnol. 46, 826835. doi: 10.1080/21691401.2018.1470525

Borrow, A. P., and Handa, R. J. (2017). Estrogen receptors modulation of anxietylike behavior. Vitam. Horm. 103, 27-52. doi: 10.1016/bs.vh.2016.08.004

Bouchard, P. R., Hutabarat, R. M., and Thompson, K. M. (2010). Discovery and development of therapeutic aptamers. Annu. Rev. Pharmacol. Toxicol. 50, 237-257. doi: 10.1146/annurev.pharmtox.010909. 105547

\section{FUNDING}

This study was supported by Guangdong Basic and Applied Basic Research Foundation (2020A1515110630), Hong Kong General Research Fund (HKBU 12114416, HKBU 12101117, HKBU 12100918, HKBU 12101018, HKBU 12103519, and HKBU 14100218), the National Key R\&D Program of China (2018YFA0800804), Interdisciplinary Research Clusters Matching Scheme of Hong Kong Baptist University (RCIRCs/17-18/02), Direct Grant of The Chinese University of Hong Kong (2018.094), and Science and Technology Innovation Commission of Shenzhen Municipality Funds (JCYJ20160229210357960).

Chi, Y. Y., Xue, J. Y., Huang, S., Xiu, B. Q., Su, Y. H., Wang, W., et al. (2019). CapG promotes resistance to paclitaxel in breast cancer through transactivation of PIK3R1/P50. Theranostics 9, 6840-6855. doi: 10.7150/thno.36338

Chiquet-Ehrismann, R., and Chiquet, M. (2003). Tenascins: regulation and putative functions during pathological stress. J. Pathol. 200, 488-499. doi: 10. 1002/path.1415

Christopeit, M., Lenz, G., Forstpointner, R., Bartelheim, K., Kuhnbach, R., Naujoks, K., et al. (2008). Nine months to progression using fourth-line liposomally encapsulated paclitaxel against hepatocellular carcinoma. Chemotherapy 54, 309-314. doi: 10.1159/000151352

Collnot, E. M., Baldes, C., Schaefer, U. F., Edgar, K. J., Wempe, M. F., and Lehr, C. M. (2010). Vitamin E TPGS P-glycoprotein inhibition mechanism: influence on conformational flexibility, intracellular ATP levels, and role of time and site of access. Mol. Pharm. 7, 642-651. doi: 10.1021/mp900191s

Cordell, G. A., Beecher, C. W. W., and Pezzuto, J. M. (1991). Can ethnopharmacology contribute to the development of new anticancer drugs. J. Ethnopharmacol. 32, 117-133. doi: 10.1016/0378-8741(91)90110-Y

Decock, J., Obermajer, N., Vozelj, S., Hendrickx, W., Paridaens, R., and Kos, J. (2008). Cathepsin B, cathepsin H, cathepsin X and cystatin C in sera of patients with early-stage and inflammatory breast cancer. Int. J. Biol. Markers 23, 161-168. doi: 10.5301/jbm.2008.3270

Dehvari, K., Chen, Y., Tsai, Y. H., Tseng, S. H., and Lin, K. S. (2016). Superparamagnetic iron oxide nanorod carriers for paclitaxel delivery in the treatment and imaging of colon cancer in mice. J. Biomed. Nanotechnol. 12, 1734-1745. doi: 10.1166/jbn.2016.2283

Delac, M., Motaln, H., Ulrich, H., and Lah, T. T. (2015). Aptamer for imaging and therapeutic targeting of brain tumor glioblastoma. Cytometry A 87, 806-816. doi: 10.1002/cyto.a.22715

Duan, T., Xu, Z., Sun, F., Wang, Y., Zhang, J., Luo, C., et al. (2019). HPA aptamer functionalized paclitaxel-loaded PLGA nanoparticles for enhanced anticancer therapy through targeted effects and microenvironment modulation. Biomed. Pharmacother. 117:109121. doi: 10.1016/j.biopha.2019. 109121

Dupont, D. M., Larsen, N., Jensen, J. K., Andreasen, P. A., and Kjems, J. (2015). Characterisation of aptamer-target interactions by branched selection and highthroughput sequencing of SELEX pools. Nucleic Acids Res. 43:e139. doi: 10. 1093/nar/gkv700

El-Dakdouki, M. H., Pure, E., and Huang, X. (2013). Development of drug loaded nanoparticles for tumor targeting. Part 2: enhancement of tumor penetration through receptor mediated transcytosis in 3D tumor models. Nanoscale 5, 3904-3911. doi: 10.1039/c3nr90022c

Engelberg, S., Netzer, E., Assaraf, Y. G., and Livney, Y. D. (2019). Selective eradication of human non-small cell lung cancer cells using aptamer-decorated nanoparticles harboring a cytotoxic drug cargo. Cell Death Dis. 10, 702-715. doi: 10.1038/s41419-019-1870-0

Esfandyari-Manesh, M., Mohammadi, A., Atyabi, F., Nabavi, S. M., Ebrahimi, S. M., Shahmoradi, E., et al. (2016). Specific targeting delivery to MUC1 overexpressing tumors by albumin-chitosan nanoparticles conjugated to DNA aptamer. Int. J. Pharm. 515, 607-615. doi: 10.1016/j.ijpharm.2016.10.066 
Fan, L., Wang, J., Xia, C., Zhang, Q., Pu, Y., Chen, L., et al. (2020). Glutathionesensitive and folate-targeted nanoparticles loaded with paclitaxel to enhance oral squamous cell carcinoma therapy. J. Mater. Chem. B 8, 3113-3122. doi: $10.1039 / \mathrm{c} 9$ tb02818h

Fujiwara, Y., Mukai, H., Saeki, T., Ro, J., Lin, Y. C., Nagai, S. E., et al. (2019). A multi-national, randomised, open-label, parallel, phase III non-inferiority study comparing NK105 and paclitaxel in metastatic or recurrent breast cancer patients. Brit. J. Cancer 120, 475-480. doi: 10.1038/s41416-019-0391-z

Galic, V. L., Wright, J. D., Lewin, S. N., and Herzog, T. J. (2011). Paclitaxel poliglumex for ovarian cancer. Expert Opin. Investig. Drugs 20, 813-821. doi: $10.1517 / 13543784.2011 .576666$

Ganipineni, L. P., Ucakar, B., Joudiou, N., Bianco, J., Danhier, P., Zhao, M., et al. (2018). Magnetic targeting of paclitaxel-loaded poly(lactic-co-glycolic acid)based nanoparticles for the treatment of glioblastoma. Int. J. Nanomedicine 13, 4509-4521. doi: 10.2147/IJN.S165184

Gao, Y., Hu, L., Liu, Y., Xu, X., and Wu, C. (2019). Targeted delivery of paclitaxel in liver cancer using hyaluronic acid functionalized mesoporous hollow alumina nanoparticles. Biomed. Res. Int. 2019:2928507. doi: 10.1155/2019/2928507

Gao, Y. Y., Chen, H., Zhou, Y. Y., Wang, L. T., Hou, Y., Xia, X. H., et al. (2017). Intraorgan targeting of gold conjugates for precise liver cancer treatment. ACS Appl. Mater. Interfaces 9, 31458-31468. doi: 10.1021/acsami.7b08969

Garofalo, M., Villa, A., Rizzi, N., Kuryk, L., Rinner, B., Cerullo, V., et al. (2019). Extracellular vesicles enhance the targeted delivery of immunogenic oncolytic adenovirus and paclitaxel in immunocompetent mice. J. Control Release 294, 165-175. doi: 10.1016/j.jconrel.2018.12.022

Georg, G. I., and Cheruvallath, Z. S. (1994). Samarium diiodide-mediated deoxygenation of taxol - a one-step synthesis of 10-deacetoxytaxol. J. Org. Chem. 59, 4015-4018. doi: 10.1021/Jo00093a040

Georg, G. I., Cheruvallath, Z. S., Himes, R. H., Mejillano, M. R., and Burke, C. T. (1992). Synthesis of biologically-active taxol analogs with modified phenylisoserine side-chains. J. Med. Chem. 35, 4230-4237. doi: 10.1021/ Jm00100a031

Giannakakou, P., Robey, R., Fojo, T., and Blagosklonny, M. V. (2001). Low concentrations of paclitaxel induce cell type-dependent p53, p21 and G1/G2 arrest instead of mitotic arrest: molecular determinants of paclitaxel-induced cytotoxicity. Oncogene 20, 3806-3813. doi: 10.1038/sj.onc.12 04487

Gong, Y. C., Xiong, X. Y., Ge, X. J., Li, Z. L., and Li, Y. P. (2019). Effect of the folate ligand density on the targeting property of folated-conjugated polymeric nanoparticles. Macromol. Biosci. 19:e1800348. doi: 10.1002/mabi.201800348

Gorain, B., Choudhury, H., Pandey, M., and Kesharwani, P. (2018). Paclitaxel loaded vitamin E-TPGS nanoparticles for cancer therapy. Mater. Sci. Eng. C Mater. Biol. Appl. 91, 868-880. doi: 10.1016/j.msec.2018.05.054

Gornstein, E., and Schwarz, T. L. (2014). The paradox of paclitaxel neurotoxicity: mechanisms and unanswered questions. Neuropharmacology 76, 175-183. doi: 10.1016/j.neuropharm.2013.08.016

Guillemard, V., and Saragovi, H. U. (2001). Taxane-antibody conjugates afford potent cytotoxicity, enhanced solubility, and tumor target selectivity. Cancer Res. 61, 694-699.

Gunatilaka, A. A. L., Ramdayal, F. D., Sarragiotto, M. H., Kingston, D. G. I., Sackett, D. L., and Hamel, E. (1999). Synthesis and biological evaluation of novel paclitaxel (Taxol) D-ring modified analogues. J. Org. Chem. 64, 2694-2703. doi: 10.1021/Jo982095h

Guo, W., Deng, L., Chen, Z., Chen, Z., Yu, J., Liu, H., et al. (2019). Vitamin B12conjugated sericin micelles for targeting CD320-overexpressed gastric cancer and reversing drug resistance. Nanomedicine (Lond) 14, 353-370. doi: 10.2217/ nnm-2018-0321

Han, L., Hu, L., Liu, F., Wang, X., Huang, X., Liu, B., et al. (2019). Redox-sensitive micelles for targeted intracellular delivery and combination chemotherapy of paclitaxel and all-trans-retinoid acid. Asian J. Pharm. Sci. 14, 531-542. doi: 10.1016/j.ajps.2018.08.009

Hanauske, A. R., Degen, D., Hilsenbeck, S. G., Bissery, M. C., and Von Hoff, D. D. (1992). Effects of taxotere and taxol on in vitro colony formation of freshly explanted human tumor cells. Anticancer Drugs 3, 121-124. doi: 10. 1097/00001813-199204000-00008

Honore, S., Pasquier, E., and Braguer, D. (2005). Understanding microtubule dynamics for improved cancer therapy. Cell Mol. Life Sci. 62, 3039-3056. doi: $10.1007 /$ s00018-005-5330-x
Husain, B., and Ellerman, D. (2018). Expanding the boundaries of biotherapeutics with bispecific antibodies. Biodrugs 32, 441-464. doi: 10.1007/s40259-0180299-9

Ibrahim, N. K., Desai, N., Legha, S., Soon-Shiong, P., Theriault, R. L., Rivera, E., et al. (2002). Phase I and pharmacokinetic study of ABI-007, a cremophor-free, protein-stabilized, nanoparticle formulation of paclitaxel. Clin. Cancer Res. 8, 1038-1044.

Iglesias, J. (2009). nab-Paclitaxel (Abraxane (R)): an albumin-bound cytotoxic exploiting natural delivery mechanisms into tumors. Breast Cancer Res. 11:S21. doi: $10.1186 /$ bcr 2282

Jain, M. M., Gupte, S. U., Patil, S. G., Pathak, A. B., Deshmukh, C. D., Bhatt, N., et al. (2016). Paclitaxel injection concentrate for nanodispersion versus nabpaclitaxel in women with metastatic breast cancer: a multicenter, randomized, comparative phase II/III study. Breast Cancer Res. Treat 156, 125-134. doi: 10.1007/s10549-016-3736-9

Jang, Y., Chung, H. J., Hong, J. W., Yun, C. W., and Chung, H. (2017). Absorption mechanism of DHP107, an oral paclitaxel formulation that forms a hydrated lipidic sponge phase. Acta Pharmacol. Sin. 38, 133-145. doi: 10.1038/aps.2016. 105

Jiang, X., Xin, H., Gu, J., Du, F., Feng, C., Xie, Y., et al. (2014). Enhanced antitumor efficacy by d-glucosamine-functionalized and paclitaxel-loaded poly(ethylene glycol)-co-poly(trimethylene carbonate) polymer nanoparticles. J .Pharm. Sci. 103, 1487-1496. doi: 10.1002/jps.23928

Jordan, M. A., Wendell, K., Gardiner, S., Derry, W. B., Copp, H., and Wilson, L. (1996). Mitotic block induced in HeLa cells by low concentrations of paclitaxel (Taxol) results in abnormal mitotic exit and apoptotic cell death. Cancer Res. 56, $816-825$.

Jupin, M., Michiels, P. J., Girard, F. C., Spraul, M., and Wijmenga, S. S. (2013). NMR identification of endogenous metabolites interacting with fatted and non-fatted human serum albumin in blood plasma: fatty acids influence the HSA-metabolite interaction. J. Magn. Reson. 228, 81-94. doi: 10.1016/j.jmr. 2012.12.010

Kavallaris, M. (2010). Microtubules and resistance to tubulin-binding agents. Nat. Rev. Cancer 10, 194-204. doi: 10.1038/nrc2803

Khongkow, P., Gomes, A. R., Gong, C., Man, E. P. S., Tsang, J. W. H., Zhao, F., et al. (2016). Paclitaxel targets FOXM1 to regulate KIF20A in mitotic catastrophe and breast cancer paclitaxel resistance. Oncogene 35, 990-1002. doi: 10.1038/onc. 2015.152

Kim, S. (2011). Integrated microfluidic platform for multiplex selex on a chip. Nucleic Acid Ther. 21, A35-A36.

Kingston, D. G. (1994). Taxol - the chemistry and structure-activity-relationships of a novel anticancer agent. Trends Biotechnol. 12, 222-227. doi: 10.1016/01677799(94)90120-1

Kinoshita, J., Fushida, S., Tsukada, T., Oyama, K., Watanabe, T., Shoji, M., et al. (2014). Comparative study of the antitumor activity of Nab-paclitaxel and intraperitoneal solvent-based paclitaxel regarding peritoneal metastasis in gastric cancer. Oncol. Rep. 32, 89-96. doi: 10.3892/or.2014.3210

Kong, H. Y., and Byun, J. (2013). Nucleic acid aptamers: new methods for selection, stabilization, and application in biomedical science. Biomol. Ther. 21, 423-434. doi: 10.4062/biomolther.2013.085

Kuznetsova, L., Chen, J., Sun, L., Wu, X. Y., Pepe, A., Veith, J. A., et al. (2006). Syntheses and evaluation of novel fatty acid-second-generation taxoid conjugates as promising anticancer agents. Bioorg. Med. Chem. Lett. 16, 974977. doi: 10.1016/j.bmcl.2005.10.089

Layek, B., Sadhukha, T., Panyam, J., and Prabha, S. (2018). Nano-engineered mesenchymal stem cells increase therapeutic efficacy of anticancer drug through true active tumor targeting. Mol. Cancer Ther. 17, 1196-1206. doi: 10.1158/1535-7163.MCT-17-0682

Le, P. N., Huynh, C. K., and Tran, N. Q. (2018). Advances in thermosensitive polymer-grafted platforms for biomedical applications. Mat. Sci. Eng. C Mater. 92, 1016-1030. doi: 10.1016/j.msec.2018.02.006

Lee, S., Lee, Y., Kim, H., Lee, D. Y., and Jon, S. (2018). Bilirubin nanoparticleassisted delivery of a small molecule-drug conjugate for targeted cancer therapy. Biomacromolecules 19, 2270-2277. doi: 10.1021/acs.biomac.8b00189

Lei, M., Ma, G., Sha, S., Wang, X., Feng, H., Zhu, Y., et al. (2019). Dualfunctionalized liposome by co-delivery of paclitaxel with sorafenib for synergistic antitumor efficacy and reversion of multidrug resistance. Drug Deliv. 26, 262-272. doi: 10.1080/10717544.2019.1580797 
Li, F., Lu, J., Liu, J., Liang, C., Wang, M., Wang, L., et al. (2017). A water-soluble nucleolin aptamer-paclitaxel conjugate for tumor-specific targeting in ovarian cancer. Nat. Commun. 8, 1390-1403. doi: 10.1038/s41467-017-01565-6

Li, H., Zhang, P., Luo, J., Hu, D., Huang, Y., Zhang, Z. R., et al. (2019). Chondroitin sulfate-linked prodrug nanoparticles target the golgi apparatus for cancer metastasis treatment. ACS Nano 13, 9386-9396. doi: 10.1021/acsnano.9b04166

Li, L., Liang, N., Wang, D., Yan, P., Kawashima, Y., Cui, F., et al. (2018). Amphiphilic polymeric micelles based on deoxycholic acid and folic acid modified chitosan for the delivery of paclitaxel. Int. J. Mol. Sci. 19:3132. doi: 10.3390/ijms19103132

Li, M., Shi, K., Tang, X., Wei, J., Cun, X., Chen, X., et al. (2018). PH-sensitive folic acid and dNP2 peptide dual-modified liposome for enhanced targeted chemotherapy of glioma. Eur. J. Pharm. Sci. 124, 240-248. doi: 10.1016/j.ejps. 2018.07.055

Li, X., Qin, F., Yang, L., Mo, L., Li, L., and Hou, L. (2014). Sulfatide-containing lipid perfluorooctylbromide nanoparticles as paclitaxel vehicles targeting breast carcinoma. Int. J. Nanomedicine 9, 3971-3985. doi: 10.2147/IJN.S67343

Li, X., Yang, Y., Jia, Y., Pu, X., Yang, T., Wang, Y., et al. (2017). Enhanced tumor targeting effects of a novel paclitaxel-loaded polymer: PEG-PCCL-modified magnetic iron oxide nanoparticles. Drug Deliv. 24, 1284-1294. doi: 10.1080/ 10717544.2017.1373167

Li, Z., Zhang, Y., Zhu, C., Guo, T., Xia, Q., Hou, X., et al. (2020). Folic acid modified lipid-bilayer coated mesoporous silica nanoparticles co-loading paclitaxel and tanshinone IIA for the treatment of acute promyelocytic leukemia. Int. J. Pharm. 586:119576. doi: 10.1016/j.ijpharm.2020.119576

Liaskoni, A., Angelopoulou, A., Voulgari, E., Popescu, M. T., Tsitsilianis, C., and Avgoustakis, K. (2018). Paclitaxel controlled delivery using a pH-responsive functional-AuNP/block-copolymer vesicular nanocarrier composite system. Eur. J. Pharm. Sci. 117, 177-186. doi: 10.1016/j.ejps.2018.02.021

Litman, G. W., Rast, J. P., Shamblott, M. J., Haire, R. N., Hulst, M., Roess, W., et al. (1993). Phylogenetic diversification of immunoglobulin genes and the antibody repertoire. Mol. Biol. Evol. 10, 60-72.

Liu, C., Jiang, W., Tian, X. B., Yang, P., Xiao, L., Li, J. L., et al. (2019). Identification of vigilin as a potential ischemia biomarker by brain slice-based systematic evolution of ligands by exponential enrichment. Anal. Chem. 91, 6675-6681. doi: 10.1021/acs.analchem.9b00609

Liu, J., Liang, N., Li, S., Han, Y., Yan, P., Kawashima, Y., et al. (2020). Tumortargeting and redox-sensitive micelles based on hyaluronic acid conjugate for delivery of paclitaxel. J. Biomater. Appl. 34, 1458-1469. doi: 10.1177/ 0885328220905256

Liu, Q. Y., and Stein, C. A. (1997). Taxol and estramustine-induced modulation of human prostate cancer cell apoptosis via alteration in bcl-x(L) and bak expression. Clin. Cancer Res. 3, 2039-2046.

Liu, Y., Zhou, C., Wang, W., Yang, J., Wang, H., Hong, W., et al. (2016). CD44 receptor targeting and endosomal $\mathrm{pH}$-sensitive dual functional hyaluronic acid micelles for intracellular paclitaxel delivery. Mol. Pharm. 13, 4209-4221. doi: 10.1021/acs.molpharmaceut.6b00870

London, N., and Biggins, S. (2014). Signalling dynamics in the spindle checkpoint response. Nat. Rev. Mol. Cell Biol. 15, 736-747. doi: 10.1038/nrm3888

Luiz, M. T., Abriata, J. P., Raspantini, G. L., Tofani, L. B., Fumagalli, F., De Melo, S. M. G., et al. (2019). In vitro evaluation of folate-modified PLGA nanoparticles containing paclitaxel for ovarian cancer therapy. Mater. Sci. Eng. C Mater. Biol. Appl. 105:110038. doi: 10.1016/j.msec.2019.110038

Luo, K., Yin, S., Zhang, R., Yu, H., Wang, G., and Li, J. (2020). Multifunctional composite nanoparticles based on hyaluronic acid-paclitaxel conjugates for enhanced cancer therapy. Int. J. Pharm. 589:119870. doi: 10.1016/j.ijpharm. 2020.119870

Luo, T., Sun, J., Zhu, S., He, J., Hao, L., Xiao, L., et al. (2017). Ultrasound-mediated destruction of oxygen and paclitaxel loaded dual-targeting microbubbles for intraperitoneal treatment of ovarian cancer xenografts. Cancer Lett. 391, 1-11. doi: 10.1016/j.canlet.2016.12.032

Luo, Y., Cai, X., Li, H., Lin, Y., and Du, D. (2016). Hyaluronic acid-modified multifunctional Q-graphene for targeted killing of drug-resistant lung cancer cells. ACS Appl. Mater. Interfaces 8, 4048-4055. doi: 10.1021/acsami.5b11471

Luo, Z., Yan, Z., Jin, K., Pang, Q., Jiang, T., Lu, H., et al. (2017). Precise glioblastoma targeting by AS1411 aptamer-functionalized poly (1-gammaglutamylglutamine)-paclitaxel nanoconjugates. J. Colloid Interface Sci. 490, 783-796. doi: 10.1016/j.jcis.2016.12.004
Lv, H., Wu, C., Liu, X., Bai, A., Cao, Y., Shang, W., et al. (2018). Folatefunctionalized mesoporous hollow $\mathrm{SnO} 2$ nanofibers as a targeting drug carrier to improve the antitumor effect of paclitaxel for liver cancer therapy. Biomed. Res. Int. 2018:8526190. doi: 10.1155/2018/8526190

Marchetti, C., Palaia, I., Giorgini, M., De Medici, C., Iadarola, R., Vertechy, L., et al. (2014). Targeted drug delivery via folate receptors in recurrent ovarian cancer: a review. Oncotargets Ther. 7, 1223-1236. doi: 10.2147/Ott.S40947

Marovich, M., Mascola, J. R., and Cohen, M. S. (2020). Monoclonal antibodies for prevention and treatment of COVID-19. J. Am. Med. Assoc. 324, 131-132. doi: 10.1001/jama.2020.10245

Marupudi, N. I., Han, J. E., Li, K. W., Renard, V. M., Tyler, B. M., and Brem, H. (2007). Paclitaxel: a review of adverse toxicities and novel delivery strategies. Expert Opin. Drug Saf. 6, 609-621. doi: 10.1517/14740338.6.5.609

Mccombs, J. R., and Owen, S. C. (2015). Antibody drug conjugates: design and selection of linker, payload and conjugation chemistry. AAPS J. 17, 339-351. doi: 10.1208/s12248-014-9710-8

Mendonsa, S. D., and Bowser, M. T. (2005). In vitro selection of aptamers with affinity for neuropeptide Y using capillary electrophoresis. J. Am. Chem. Soc. 127, 9382-9383. doi: 10.1021/ja052406n

Mie, M., Matsumoto, R., Mashimo, Y., Cass, A. E. G., and Kobatake, E. (2019). Development of drug-loaded protein nanoparticles displaying enzymaticallyconjugated DNA aptamers for cancer cell targeting. Mol. Biol. Rep. 46, 261-269. doi: 10.1007/s11033-018-4467-2

Mo, J., Eggers, P. K., Yuan, Z. X., Raston, C. L., and Lim, L. Y. (2016). Paclitaxelloaded phosphonated calixarene nanovesicles as a modular drug delivery platform. Sci. Rep. 6:23489. doi: 10.1038/srep23489

Monaco, I., Camorani, S., Colecchia, D., Locatelli, E., Calandro, P., Oudin, A., et al. (2017). Aptamer functionalization of nanosystems for glioblastoma targeting through the blood-brain barrier. J. Med. Chem. 60, 4510-4516. doi: 10.1021/ acs.jmedchem.7b00527

Mongelard, F., and Bouvet, P. (2010). AS-1411, a guanosine-rich oligonucleotide aptamer targeting nucleolin for the potential treatment of cancer, including acute myeloid leukemia. Curr. Opin. Mol. Ther. 12, 107-114.

New, P. Z., Jackson, C. E., Rinaldi, D., Burris, H., and Barohn, R. J. (1996). Peripheral neuropathy secondary to docetaxel (Taxotere). Neurology 46, 108111. doi: $10.1212 / \mathrm{wnl} .46 .1 .108$

Ni, S., Zhuo, Z., Pan, Y., Yu, Y., Li, F., Liu, J., et al. (2020). Recent progress in aptamer discoveries and modifications for therapeutic applications. ACS Appl. Mater. Interfaces. 8, 9500-9519. doi: 10.1021/acsami.0c05750

Nicolaou, K. C., Renaud, J., Nantermet, P. G., Couladouros, E. A., Guy, R. K., and Wrasidlo, W. (1995). Chemical synthesis and biological evaluation of C-2 taxoids. J. Am. Chem. Soc. 117, 2409-2420. doi: 10.1021/Ja00114a005

Oh, S. S., Lee, B. F., Leibfarth, F. A., Eisenstein, M., Robb, M. J., Lynd, N. A., et al. (2014). Synthetic aptamer-polymer hybrid constructs for programmed drug delivery into specific target cells. J. Am. Chem. Soc. 136, 15010-15015. doi: $10.1021 /$ ja5079464

Ojima, I. (2008). Guided molecular missiles for tumor-targeting chemotherapycase studies using the second-generation taxolds as warheads. Acc. Chem. Res. 41, 108-119. doi: 10.1021/ar700093f

Ojima, I., Geng, X. D., Wu, X. Y., Qu, C. X., Borella, C. P., Xie, H. S., et al. (2002). Tumor-specific novel taxoid-monoclonal antibody conjugates. J. Med. Chem. 45, 5620-5623. doi: $10.1021 / \mathrm{jm} 025540 \mathrm{~g}$

Ojima, I., Zuniga, E. S., Berger, W. T., and Seitz, J. D. (2012). Tumor-targeting drug delivery of new-generation taxoids. Future Med. Chem. 4, 33-50. doi: 10.4155/Fmc.11.167

Park, J., Park, J. E., Hedrick, V. E., Wood, K. V., Bonham, C., Lee, W., et al. (2018). A comparative in vivo study of albumin-coated paclitaxel nanocrystals and abraxane. Small 14:e1703670. doi: 10.1002/Smll.201703670

Pascucci, L., Cocce, V., Bonomi, A., Ami, D., Ceccarelli, P., Ciusani, E., et al. (2014). Paclitaxel is incorporated by mesenchymal stromal cells and released in exosomes that inhibit in vitro tumor growth: a new approach for drug delivery. J. Control Release 192, 262-270. doi: 10.1016/j.jconrel.2014.07.042

Platt, V. M., and Szoka, F. C. Jr. (2008). Anticancer therapeutics: targeting macromolecules and nanocarriers to hyaluronan or CD44, a hyaluronan receptor. Mol. Pharm. 5, 474-486. doi: 10.1021/mp800024g

Puvvada, N., Rajput, S., Kumar, B. N. P., Sarkar, S., Konar, S., Brunt, K. R., et al. (2015). Novel ZnO hollow-nanocarriers containing paclitaxel targeting folate-receptors in a malignant $\mathrm{pH}$-microenvironment for effective 
monitoring and promoting breast tumor regression. Sci. Rep. 5:11760. doi: 10.1038/srep 11760

Qu, D., Jiao, M., Lin, H., Tian, C., Qu, G., Xue, J., et al. (2020). Anisamidefunctionalized $\mathrm{pH}$-responsive amphiphilic chitosan-based paclitaxel micelles for sigma-1 receptor targeted prostate cancer treatment. Carbohydr. Polym. 229:115498. doi: 10.1016/j.carbpol.2019.115498

Quiles, S., Raisch, K. P., Sanford, L. L., Bonner, J. A., and Safavy, A. (2010). Synthesis and preliminary biological evaluation of high-drug-load paclitaxelantibody conjugates for tumor-targeted chemotherapy. J. Med. Chem. 53, 586-594. doi: 10.1021/jm900899g

Ramanathan, B., Jan, K. Y., Chen, C. H., Hour, T. C., Yu, H. J., and Pu, Y. S. (2005). Resistance to paclitaxel is proportional to cellular total antioxidant capacity. Cancer Res. 65, 8455-8460. doi: 10.1158/0008-5472.CAN-05-1162

Ravar, F., Saadat, E., Gholami, M., Dehghankelishadi, P., Mahdavi, M., Azami, S., et al. (2016). Hyaluronic acid-coated liposomes for targeted delivery of paclitaxel, in-vitro characterization and in-vivo evaluation. J. Control Release 229, 10-22. doi: 10.1016/j.jconrel.2016.03.012

Régina, A., Demeule, M., Che, C., Lavallee, I., Poirier, J., Gabathuler, R., et al. (2008). Antitumour activity of ANG1005, a conjugate between paclitaxel and the new brain delivery vector Angiopep-2. Brit. J. Pharmacol. 155, 185-197. doi: $10.1038 /$ bjp. 2008.260

Rosenberg, J. E., Bambury, R. M., Van Allen, E. M., Drabkin, H. A., Lara, P. N. Jr., Harzstark, A. L., et al. (2014). A phase II trial of AS1411 (a novel nucleolintargeted DNA aptamer) in metastatic renal cell carcinoma. Invest. New Drugs 32, 178-187. doi: 10.1007/s10637-013-0045-6

Rowinsky, E. K., Cazenave, L. A., and Donehower, R. C. (1990). Taxol: a novel investigational antimicrotubule agent. J. Natl. Cancer Inst. 82, 1247-1259. doi: $10.1093 /$ jnci/82.15.1247

Schiff, P. B., Fant, J., and Horwitz, S. B. (1979). Promotion of microtubule assembly in vitro by taxol. Nature 277, 665-667. doi: 10.1038/277665a0

Shen, M., Huang, Y., Han, L., Qin, J., Fang, X., Wang, J., et al. (2012). Multifunctional drug delivery system for targeting tumor and its acidic microenvironment. J. Control Release 161, 884-892. doi: 10.1016/j.jconrel.2012. 05.013

Shi, S., Fu, W., Lin, S., Tian, T., Li, S., Shao, X., et al. (2019). Targeted and effective glioblastoma therapy via aptamer-modified tetrahedral framework nucleic acidpaclitaxel nanoconjugates that can pass the blood brain barrier. Nanomedicine 21:102061. doi: 10.1016/j.nano.2019.102061

Silva, D., Cortez, C. M., Silva, C. M., and Missailidis, S. (2013). A fluorescent spectroscopy and modelling analysis of anti-heparanase aptamers-serum protein interactions. J. Photochem. Photobiol. B 127, 68-77. doi: 10.1016/j. jphotobiol.2013.06.015

Singer, J. W. (2005). Paclitaxel poliglumex (XYOTAX, CT-2103): a macromolecular taxane. J. Control Release 109, 120-126. doi: 10.1016/j.jconrel.2005.09.033

Smith, T. A. (1999). Facilitative glucose transporter expression in human cancer tissue. Br. J. Biomed. Sci. 56, 285-292.

Sorger, P. K., Dobles, M., Tournebize, R., and Hyman, A. A. (1997). Coupling cell division and cell death to microtubule dynamics. Curr. Opin. Cell Biol. 9, 807-814. doi: 10.1016/S0955-0674(97)80081-6

Srinivasarao, M., and Low, P. S. (2017). Ligand-targeted drug delivery. Chem. Rev. 117, 12133-12164. doi: 10.1021/acs.chemrev.7b00013

Stoltenburg, R., Reinemann, C., and Strehlitz, B. (2005). FluMag-SELEX as an advantageous method for DNA aptamer selection. Anal. Bioanal. Chem. 383, 83-91. doi: 10.1007/s00216-005-3388-9

Su, Y., Liu, Y., Xu, X., Zhou, J., Xu, L., Xu, X., et al. (2018). On-demand versatile prodrug nanomicelle for tumor-specific bioimaging and photothermal-chemo synergistic cancer therapy. ACS Appl. Mater. Interfaces 10, 38700-38714. doi: 10.1021/acsami.8b11349

Sun, H. G., Tan, W. H., and Zu, Y. L. (2016). Aptamers: versatile molecular recognition probes for cancer detection. Analyst 141, 403-415. doi: 10.1039/ c5an01995h

Sun, X., Chen, Y., Zhao, H., Qiao, G., Liu, M., Zhang, C., et al. (2018). Dualmodified cationic liposomes loaded with paclitaxel and survivin siRNA for targeted imaging and therapy of cancer stem cells in brain glioma. Drug Deliv. 25, 1718-1727. doi: 10.1080/10717544.2018.1494225

Takakura, K., Kawamura, A., Torisu, Y., Koido, S., Yahagi, N., and Saruta, M. (2019). The clinical potential of oligonucleotide therapeutics against pancreatic cancer. Int. J. Mol. Sci. 20:3331. doi: 10.3390/Ijms20133331
Tan, A. R., Hanauske, A. R., Gelderblom, H., Scheulen, M. E., Van Warmerdam, L. J., Rosing, H., et al. (2006). Results of a clinical pharmacokinetic (PK) bioequiulence (BE) study of liposomal paclitaxel (LEP-ETU) versus paclitaxel (T) in patients with advanced cancer. J. Clin. Oncol. 24, 83s-83s.

Tang, H., Chen, J., Wang, L., Li, Q., Yang, Y., Lv, Z., et al. (2020). Co-delivery of epirubicin and paclitaxel using an estrone-targeted PEGylated liposomal nanoparticle for breast cancer. Int. J. Pharm. 573:118806. doi: 10.1016/j. ijpharm.2019.118806

Tang, Y., Chen, M., Xie, Q., Li, L., Zhu, L., Ma, Q., et al. (2020). Construction and evaluation of hyaluronic acid-based copolymers as a targeted chemotherapy drug carrier for cancer therapy. Nanotechnology 31:305702. doi: 10.1088/1361$6528 / \mathrm{ab} 884 \mathrm{~d}$

Thomas, R. G., Moon, M., Lee, S., and Jeong, Y. Y. (2015). Paclitaxel loaded hyaluronic acid nanoparticles for targeted cancer therapy: in vitro and in vivo analysis. Int. J. Biol. Macromol. 72, 510-518. doi: 10.1016/j.ijbiomac.2014.08. 054

Tran, P. H., Tran, T. T., and Lee, B. J. (2014). Biodistribution and pharmacokinetics in rats and antitumor effect in various types of tumor-bearing mice of novel self-assembled gelatin-oleic acid nanoparticles containing paclitaxel. J. Biomed. Nanotechnol. 10, 154-165. doi: 10.1166/jbn.2014.1660

Urandur, S., Banala, V. T., Shukla, R. P., Mittapelly, N., Pandey, G., Kalleti, N., et al. (2018). Anisamide-anchored lyotropic nano-liquid crystalline particles with AIE effect: a smart optical beacon for tumor imaging and therapy. ACS Appl. Mater. Interfaces 10, 12960-12974. doi: 10.1021/acsami.7b 19109

Vergote, I., and Leamon, C. P. (2015). Vintafolide: a novel targeted therapy for the treatment of folate receptor expressing tumors. Ther. Adv. Med. Oncol. 7, 206-218. doi: 10.1177/1758834015584763

Vineberg, J. G., Wang, T., Zuniga, E. S., and Ojima, I. (2015). Design, synthesis, and biological evaluation of theranostic vitamin-linker-taxoid conjugates. J. Med. Chem. 58, 2406-2416. doi: 10.1021/jm5019115

Vinothini, K., Rajendran, N. K., Ramu, A., Elumalai, N., and Rajan, M. (2019). Folate receptor targeted delivery of paclitaxel to breast cancer cells via folic acid conjugated graphene oxide grafted methyl acrylate nanocarrier. Biomed. Pharmacother. 110, 906-917. doi: 10.1016/j.biopha.2018.12.008

Wahl, A., Guerittevoegelein, F., Guenard, D., Legoff, M. T., and Potier, P. (1992). Rearrangement reactions of taxanes - structural modifications of 10deacetylbaccatin-III. Tetrahedron 48, 6965-6974. doi: 10.1016/S0040-4020(01) 91208-6

Wang, G., Wang, Z., Li, C., Duan, G., Wang, K., Li, Q., et al. (2018). RGD peptidemodified, paclitaxel prodrug-based, dual-drugs loaded, and redox-sensitive lipid-polymer nanoparticles for the enhanced lung cancer therapy. Biomed. Pharmacother. 106, 275-284. doi: 10.1016/j.biopha.2018.06.137

Wang, H., Vo, T., Hajar, A., Li, S., Chen, X. M., Parissenti, A. M., et al. (2014). Multiple mechanisms underlying acquired resistance to taxanes in selected docetaxel-resistant MCF-7 breast cancer cells. BMC Cancer 14:37. doi: 10.1186/ 1471-2407-14-37

Wang, Y. L., Zhou, Y., Zheng, Z. N., Li, J. T., Yan, Y. T., and Wu, W. (2018). Sulforaphane metabolites reduce resistance to paclitaxel via microtubule disruption. Cell Death Dis. 9:1134.

Wani, M. C., Taylor, H. L., Wall, M. E., Coggon, P., and Mcphail, A. T. (1971). Plant antitumor agents. VI. the isolation and structure of taxol, a novel antileukemic and antitumor agent from Taxus brevifolia. J. Am. Chem. Soc. 93, 2325-2327. doi: $10.1021 /$ ja00738a045

Weaver, B. A. (2014). How Taxol/paclitaxel kills cancer cells. Mol. Biol. Cell 25, 2677-2681. doi: 10.1091/mbc.E14-04-0916

Wilson, L., Panda, D., and Jordan, M. A. (1999). Modulation of microtubule dynamics by drugs: a paradigm for the actions of cellular regulators. Cell Struct. Funct. 24, 329-335. doi: 10.1247/Csf.24.329

Wu, D., Zheng, Y., Hu, X., Fan, Z., and Jing, X. (2015). Anti-tumor activity of folate targeted biodegradable polymer-paclitaxel conjugate micelles on EMT6 breast cancer model. Mater. Sci. Eng. C Mater. Biol. Appl. 53, 68-75. doi: 10.1016/j.msec.2015.04.012

Wu, J., Song, C., Jiang, C., Shen, X., Qiao, Q., and Hu, Y. (2013). Nucleolin targeting AS1411 modified protein nanoparticle for antitumor drugs delivery. Mol. Pharm. 10, 3555-3563. doi: 10.1021/mp300686g

Wu, J., Zhang, J., Deng, C., Meng, F., and Zhong, Z. (2016). Vitamin E-oligo(methyl diglycol l-glutamate) as a biocompatible and functional surfactant for facile 
preparation of active tumor-targeting PLGA nanoparticles. Biomacromolecules 17, 2367-2374. doi: 10.1021/acs.biomac.6b00380

Wu, M., Wang, Y., Wang, Y. R., Zhang, M. B., Luo, Y. K., Tang, J., et al. (2017). Paclitaxel-loaded and A10-3.2 aptamer-targeted poly(lactide-co-glycolic acid) nanobubbles for ultrasound imaging and therapy of prostate cancer. Int. J. Nanomed. 12, 5313-5330. doi: 10.2147/Ijn.S136032

Wu, X., Li, F., Li, Y., Yu, Y., Liang, C., Zhang, B., et al. (2020). A PD-L1 aptamer selected by loss-gain cell-SELEX conjugated with paclitaxel for treating triple-negative breast cancer. Med. Sci. Monit. 26:e925583. doi: 10.12659/MSM. 925583

Xiao, Y., Wang, S., Zong, Q., and Yin, Z. (2018). Co-delivery of metformin and paclitaxel via folate-modified $\mathrm{pH}$-sensitive micelles for enhanced anti-tumor efficacy. AAPS PharmSciTech 19, 2395-2406. doi: 10.1208/s12249-018-1070-8

Xie, J., Lee, S., and Chen, X. (2010). Nanoparticle-based theranostic agents. Adv. Drug Deliv. Rev. 62, 1064-1079. doi: 10.1016/j.addr.2010.07.009

Xu, C., Liu, W., Hu, Y., Li, W., and Di, W. (2020). Bioinspired tumor-homing nanoplatform for co-delivery of paclitaxel and siRNA-E7 to HPV-related cervical malignancies for synergistic therapy. Theranostics 10, 3325-3339. doi: 10.7150/thno.41228

Yang, X. Y., Li, Y. X., Li, M., Zhang, L., Feng, L. X., and Zhang, N. (2013). Hyaluronic acid-coated nanostructured lipid carriers for targeting paclitaxel to cancer. Cancer Lett. 334, 338-345. doi: 10.1016/j.canlet.2012.07.002

Yang, Y., Zhao, Z., Xie, C., and Zhao, Y. (2020). Dual-targeting liposome modified by glutamic hexapeptide and folic acid for bone metastatic breast cancer. Chem. Phys. Lipids 228:104882. doi: 10.1016/j.chemphyslip.2020.104882

Yao, H. Z., Jiang, F., Lu, A. P., and Zhang, G. (2016). Methods to design and synthesize antibody-drug conjugates (ADCs). Int. J. Mol. Sci. 17:194. doi: 10. 3390/Ijms17020194

Yao, S., Li, L., Su, X. T., Wang, K., Lu, Z. J., Yuan, C. Z., et al. (2018). Development and evaluation of novel tumor-targeting paclitaxel-loaded nano-carriers for ovarian cancer treatment: in vitro and in vivo. J. Exp. Clin. Cancer Res. 37:29. doi: 10.1186/s13046-018-0700-Z

Ye, L., He, J., Hu, Z. P., Dong, Q. J., Wang, H. B., Fu, F. H., et al. (2013). Antitumor effect and toxicity of Lipusu in rat ovarian cancer xenografts. Food Chem. Toxicol. 52, 200-206. doi: 10.1016/j.fct.2012.11.004

Yin, R., Pan, J., Zhou, B. S., Zhang, Y. B., Dougherty, J., Liu, J. N., et al. (2013). Evaluation of the toxicity and efficacy of paclitaxel nanoencapsulated with polyethyloxazoline polymers. J. Clin. Oncol. 31:e13538. doi: 10.1200/jco.2013. 31.15_suppl.e13538

Yin, S., Huai, J., Chen, X., Yang, Y., Zhang, X., Gan, Y., et al. (2015). Intracellular delivery and antitumor effects of a redox-responsive polymeric paclitaxel conjugate based on hyaluronic acid. Acta Biomater. 26, 274-285. doi: 10.1016/j. actbio.2015.08.029

Yu, C., Hu, Y., Duan, J., Yuan, W., Wang, C., Xu, H., et al. (2011). Novel aptamer-nanoparticle bioconjugates enhances delivery of anticancer drug to MUC1-positive cancer cells in vitro. PLoS One 6:e24077. doi: 10.1371/journal. pone.0024077

Yu, S., Bi, X., Yang, L., Wu, S., Yu, Y., Jiang, B., et al. (2019). Codelivery of paclitaxel and PLK1-targeted siRNA using aptamer-functionalized cationic liposome for synergistic anti-breast cancer effects in vivo. J. Biomed. Nanotechnol. 15, 1135-1148. doi: 10.1166/jbn.2019.2751

Zamay, G. S., Kolovskaya, O. S., Ivanchenko, T. I., Zamay, T. N., Veprintsev, D. V., Grigorieva, V. L., et al. (2019). Development of DNA aptamers to native EpCAM for isolation of lung circulating tumor cells from human blood. Cancers (Basel) 11:351. doi: 10.3390/cancers11030351

Zhang, M., Ma, Y., Wang, Z., Han, Z., Gao, W., Zhou, Q., et al. (2019). A CD44targeting programmable drug delivery system for enhancing and sensitizing chemotherapy to drug-resistant cancer. ACS Appl. Mater. Interfaces 11, 58515861. doi: 10.1021/acsami.8b19798

Zhang, Q., Zhao, J., Hu, H., Yan, Y., Hu, X., Zhou, K., et al. (2019). Construction and in vitro and in vivo evaluation of folic acid-modified nanostructured lipid carriers loaded with paclitaxel and chlorin e6. Int. J. Pharm. 569:118595. doi: 10.1016/j.ijpharm.2019.118595

Zhang, X., Ren, X., Tang, J., Wang, J., Zhang, X., He, P., et al. (2020). Hyaluronic acid reduction-sensitive polymeric micelles achieving co-delivery of tumor-targeting paclitaxel/apatinib effectively reverse cancer multidrug resistance. Drug Deliv. 27, 825-835. doi: 10.1080/10717544.2020.1770373

Zhang, Y., Huang, Y., Zhao, W., Lu, J., Zhang, P., Zhang, X., et al. (2014). Fmocconjugated PEG-vitamin E2 micelles for tumor-targeted delivery of paclitaxel: enhanced drug-carrier interaction and loading capacity. AAPS J. 16, 1282-1291. doi: 10.1208/s12248-014-9651-2

Zhao, J., Wan, Z., Zhou, C., Yang, Q., Dong, J., Song, X., et al. (2018). Hyaluronic acid layer-by-layer (LbL) nanoparticles for synergistic chemo-phototherapy. Pharm. Res. 35:196. doi: 10.1007/s11095-018-2480-8

Zhao, L., Bi, D., Qi, X., Guo, Y., Yue, F., Wang, X., et al. (2019). Polydopaminebased surface modification of paclitaxel nanoparticles for osteosarcoma targeted therapy. Nanotechnology 30:255101. doi: 10.1088/1361-6528/ab055f

Zhao, P., Wang, H., Yu, M., Liao, Z., Wang, X., Zhang, F., et al. (2012). Paclitaxel loaded folic acid targeted nanoparticles of mixed lipid-shell and polymer-core: in vitro and in vivo evaluation. Eur. J. Pharm. Biopharm. 81, 248-256. doi: 10.1016/j.ejpb.2012.03.004

Zhao, Z., Xu, L., Shi, X., Tan, W., Fang, X., and Shangguan, D. (2009). Recognition of subtype non-small cell lung cancer by DNA aptamers selected from living cells. Analyst 134, 1808-1814. doi: 10.1039/b904476k

Zheng, X. C., Ren, W., Zhang, S., Zhong, T., Duan, X. C., Yin, Y. F., et al. (2018). The theranostic efficiency of tumor-specific, $\mathrm{pH}$-responsive, peptidemodified, liposome-containing paclitaxel and superparamagnetic iron oxide nanoparticles. Int. J. Nanomedicine 13, 1495-1504. doi: 10.2147/IJN.S157082

Zhong, P., Chen, X., Guo, R., Chen, X., Chen, Z., Wei, C., et al. (2020). Folic acid-modified nanoerythrocyte for codelivery of paclitaxel and tariquidar to overcome breast cancer multidrug resistance. Mol. Pharm. 17, 1114-1126. doi: 10.1021/acs.molpharmaceut.9b01148

Zhong, Y., Goltsche, K., Cheng, L., Xie, F., Meng, F., Deng, C., et al. (2016). Hyaluronic acid-shelled acid-activatable paclitaxel prodrug micelles effectively target and treat CD44-overexpressing human breast tumor xenografts in vivo. Biomaterials 84, 250-261. doi: 10.1016/j.biomaterials.2016.01.049

Zhu, A. J., Yuan, P., Du, F., Hong, R. X., Ding, X. Y., Shi, X. Q., et al. (2016). SPARC overexpression in primary tumors correlates with disease recurrence and overall survival in patients with triple-negative breast cancer. Oncotarget 7 , 76628-76634. doi: 10.18632/oncotarget.10532

Zhu, D., Wu, S., Hu, C., Chen, Z., Wang, H., Fan, F., et al. (2017). Folate-targeted polymersomes loaded with both paclitaxel and doxorubicin for the combination chemotherapy of hepatocellular carcinoma. Acta Biomater. 58, 399-412. doi: 10.1016/j.actbio.2017.06.017

Zhuang, C. L., Guan, X. H., Ma, H., Cong, H., Zhang, W. N., and Miao, Z. Y. (2019). Small molecule-drug conjugates: a novel strategy for cancer-targeted treatment. Eur. J. Med. Chem. 163, 883-895. doi: 10.1016/j.ejmech.2018.12.035

Zierhut, C., Yamaguchi, N., Paredes, M., Luo, J. D., Carroll, T., and Funabiki, H. (2019). The cytoplasmic DNA sensor cGAS promotes mitotic cell death. Cell 178, 302-315e.23. doi: 10.1016/j.cell.2019.05.035

Zou, J., Su, S., Chen, Z., Liang, F., Zeng, Y., Cen, W., et al. (2019). Hyaluronic acid-modified selenium nanoparticles for enhancing the therapeutic efficacy of paclitaxel in lung cancer therapy. Artif. Cells Nanomed. Biotechnol. 47, 3456-3464. doi: 10.1080/21691401.2019.1626863

Conflict of Interest: BZ and AK were employed by the company Increasepharm (Hong Kong) Limited. JG was employed by the company Increasepharm (Hengqin) Institute Co., Limited.

The remaining authors declare that the research was conducted in the absence of any commercial or financial relationships that could be construed as a potential conflict of interest.

Copyright $\odot 2021 \mathrm{Ma}, \mathrm{Yu}$, Ni, Zhang, Kung, Gao, Lu and Zhang. This is an openaccess article distributed under the terms of the Creative Commons Attribution License (CC BY). The use, distribution or reproduction in other forums is permitted, provided the original author(s) and the copyright owner(s) are credited and that the original publication in this journal is cited, in accordance with accepted academic practice. No use, distribution or reproduction is permitted which does not comply with these terms. 